Supplement of Atmos. Chem. Phys., 14, 10333-10362, 2014

http://www.atmos-chem-phys.net/14/10333/2014/

doi:10.5194/acp-14-10333-2014-supplement

(C) Author(s) 2014. CC Attribution 3.0 License.

(c) (1)

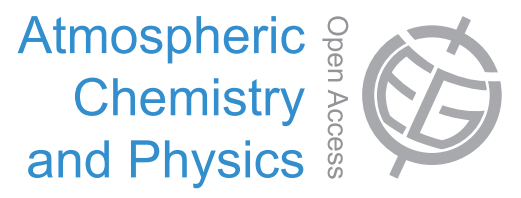

Supplement of

\title{
The balances of mixing ratios and segregation intensity: a case study from the field (ECHO 2003)
}

R. Dlugi et al.

Correspondence to: R. Dlugi (rdlugi@gmx.de) and A. Hofzumahaus (a.hofzumahaus@fz-juelich.de) 


\section{Introduction}

In this supplement we summarize various additional information for the paper "Balances of Mixing Ratios and Segregation Intensity: A Case Study from the Field (ECHO 2003)" especially on the field site and the experimental set-up and on additional findings on the variability of meteorological and chemical conditions for July 25, 2003 of the ECHO field study. In addition, we provide some more details on the direct and indirect influences of advection of isoprene and other compounds on segregation intensity.

Further information is also presented by Dlugi et al. [2010], Schaub [2007], Spirig et al. [2005], Bohn [2006], Bohn and Rohrer [2006]. In the related paper we focus on relationships between terms influencing the segregation intensity $I_{S}$ and other parameters. Additional findings - e.g. on the dependence of the correlation coefficient $r_{i j}$ on the mixing ratios or the reaction rate - are given here. We also add results on our analysis on empirical relationships found between $I_{S}$ and terms of the balance equation. In addition, some information on our analysis on mixing processes near canopy top and on a foot-print analysis will give hints on the influence of the heterogeneous distribution of isoprene sources around the main tower.

\section{Measurements}

\section{$2.1 \quad$ Field Site}

The location of the maintower and the spatial distribution of vegetation types are described in detail by Spirig et al. [2005], Ammann et al. [2004], Aubrun et al. [2005]. The vegetation is mainly composed of beech, birch and oak tree species. The west tower is situated in an oak stand. The main tower is surrounded by $90 \%$ beeches and $10 \%$ birches. The nearest oak stand is in a distance of about $30-70 \mathrm{~m}$ to the SW to SE with a decreasing amount of these species in the sector SE to E. The distance between west- and main - tower is about $225 \mathrm{~m}$. The oak stand extends from the west-tower to the East up to about $40 \mathrm{~m}$ where the beech stand is located with the main tower at its Eastern border. From the main tower to the East the vegetation is mainly composed of a mixed beech oak forest. The mean leaf area index is $L A I \approx 5$ with the mean canopy height $h_{c} \approx 30 \mathrm{~m}$ at the area of the main tower.

\subsection{PTR-MS instrument}

The principle operation of the PTR-MS follows the procedures as given by Ammann et al. [2004], Spirig et al. [2005], Dlugi et al. [2010] and is shortly summarised in the following. Air was pulled through an inlet of a tube down to the ground where the PTR-MS was installed in a field laboratory-container. The ion masses (m) at m 69 (isoprene), m 71 (sum of MACR and MVK) and at m 137 (and m 81) (sum of monoterpenes) together with $\mathrm{m} 21\left(\mathrm{H}_{3} \mathrm{O}-18^{+}\right)$were recorded in an alternating cycle. The measuring cycle is, therefore, comparable to the cycle given by Spirig et al. [2005] in their Fig. 2. The single ion masses are recorded with $0.2 \mathrm{~Hz}$ other than by Spirig et al. [2005] with about $0.3 \mathrm{~Hz}$. For calibration during the complete campaign, gas standards for methanol, ethanol, acetone, acetaldehyde, isoprene and $\alpha$-pinene from Apel-Riemer, Environmental Inc., Denver, CO, USA were applied. The zero point was determined hourly with an intermission of $300 \mathrm{~s}$ to $420 \mathrm{~s}$ of the measurements visible in the related time series (Fig. 5 - 8). Other operational parameter were fixed as given by Spirig et al. [2005] in their Table 1 for the main tower also, with a total residence time of the sample gas from the inlet tube (at $37 \mathrm{~m}$ height) to the drift tube of the PTR-MS at ground level of about 1s (see also Dlugi et al. [2010]). The mean mixing ratios for each time interval are given in Fig. 8.

\subsection{Operation of LIF instrument}

As described by Dlugi et al. [2010], the LIF instrument of Forschungszentrum Jülich was based on the concept used previously by the same group [Holland et al., 1995, 2003]. The radicals are sampled by expansion of ambient air through an inlet nozzle into a low pressure chamber, where $\mathrm{OH}$ is detected by LIF at $308 \mathrm{~nm} . \mathrm{HO}_{2}$ radicals are monitored in a separate detection chamber, in which $\mathrm{HO}_{2}$ is first chemically converted to $\mathrm{OH}$ by reaction with $\mathrm{NO}$, followed by LIF detection of $\mathrm{OH}$. The $\mathrm{OH}$ fluorescence is excited by a pulsed narrow-bandwidth UV laser system and is detected by gated photon-counting after each laser pulse. The laser can be tuned on- and off-resonance to distinguish the $\mathrm{OH}$ fluorescence signal from non-resonant background signals [Hofzumahaus et al., 1996]. Calibration is performed by known amounts of $\mathrm{OH}$ radicals which are generated by photolysis of water vapor at $185 \mathrm{~nm}$ [Holland et al., 2003].

The LIF instrument signals were obtained in the way as described by Dlugi et al. [2010] and are given for the on- and off- resonance signals in Fig. 4. The difference between the on- and off- resonance 
signals is a measure of the $\mathrm{OH}$ - fluorescence which was converted into concentration data by means of the calibrated detection sensitivity. Resulting $\mathrm{HO}_{\mathrm{x}}$ data are available during the following time blocks: 09:34 - 10:18, 10:25 - 11:30, 11:37 - 12:33, 12:39 - 13:38, 13:44 - 14:19 CET with the calibration procedure in between (Fig. 5, 6). The gaps in between are the time intervals when the laser was off-resonance.

Note that a statistical Z-test [Sachs and Hedderich, 2006] is applied to both data sets to estimate if the variability of the signals (Figs. 4,5 ) is influenced by the precision of measurements. For this purpose the deviations of signals from their mean of consecutive $10 \mathrm{~min}$ intervals are considered for a confidence level of $\alpha=0.05$ (e.g. there is only a chance of rejecting the null hypothesis by $5 \%$ ). For OH only about one third of the intervals fulfil this criteria with $\alpha=0.05$. For $\alpha=0.15$ in $88 \%$ of the 10 min-intervals the variability of the signals appears to be real and not caused by the precision of the measurements. These criteria are more restrictive than the determination of the standard error $\Delta a$ (Fig. 5, 6) which shows that $\Delta a(\mathrm{OH})$ and $\Delta a\left(\mathrm{HO}_{2}\right)$ are well below $10 \%$ of their specific mean concentrations. One should be aware that for the further analysis and discussion, the calculated smallest $\mathrm{OH}$ - fluxes are still influenced by measurement precision [Dlugi et al., 2010]. This has an effect on the estimation of the term $T_{P O H}$ in Eq. (9) in the paper, but does not change our conclusions because only smallest values $\left(10^{-6} \mathrm{ppb}^{2} \mathrm{~s}^{-1}\right)$ are less precise.

For the consideration of segregation it is important to note that a time resolution of $0.2 \mathrm{~Hz}$ was chosen, which allowed to apply the same procedures of time series analysis to the data from LIF and PTR-MS instruments and to estimate $\mathrm{I}_{s}$ according to Eq. (7) in the paper.

\subsection{Measurements with sonic anemometer}

The sonic anemometer METEK USA-1 sensor at $37 \mathrm{~m}$ height was installed as near as possible to the inlets of the PTR-MS and LIF instruments ( $0.45 \mathrm{~m}$ away from the PTR-MS and $0.6 \mathrm{~m}$ away from the LIF inlet). As described by Dlugi et al. [2010] the raw data also contain the exact time stamp, therefore, even small delays in each individual signal could be corrected (Section 2.5). The three wind vector components $(u, \vec{v}, w)$ and the sonic temperature $\left(\mathrm{T}_{s}\right)$ were recorded with $10 \mathrm{~Hz}$ and post processed together with the data from PTR-MS and LIF. A 3-D sensor correction based on detailed measurements in a wind tunnel of the Meteorological Institute, University Hamburg, Germany was applied to correct wind vector components raw data for the influence of flow distortion. Further details are discussed by Dlugi et al. $[2010]$.

\subsection{Application of the covariance method}

Every turbulent time series of wind vector components, temperature, humidity and trace substances show time dependent trends of their means over each integration interval $\Delta$, which have to be eliminated to calculate covariances. Thus, a low frequency instationarity is separated from a higher-frequency turbulence. In our analysis, the trend correction for $1 \mathrm{~min}$ up to $10 \mathrm{~min}$ data is performed by a cubic polynom, while for the $30 \mathrm{~min}$ data a symmetric linear Savitzki-Golay low pass filter signal (Press et al., 2001 ) is subtracted from the initial data set. This net signal is added to the arithmetic mean. This procedure minimizes the resulting residuum even better than linear detrending, while the mean value is conserved. A corresponding test for stationarity with consecutive $2 \mathrm{~min}$ samples within $\Delta=10 \mathrm{~min}$ and 5 min samples within $\Delta=30 \mathrm{~min}$ as described by Foken et al. [1995] shows that all covariances fulfilled a criterion $0.8<\left(\overline{w^{\prime} \rho^{\prime}}{ }_{i}\right)_{2 \mathrm{~min}} /\left(\overline{w^{\prime} \rho^{\prime}}{ }_{i}\right)_{10 \mathrm{~min}}<1.2$ for stationarity. This is even stronger than the $30 \%$ criterion for $\Delta=30 \mathrm{~min}$ which is often applied [e.g. Spirig et al., 2005, Farmer et al., 2006].

The further calculation of turbulent and micrometeorological mean quantities is performed in the way as described by Dlugi et al. [2010] and shortly repeated in the following. After applying the trend correction, the first to fourth moments are calculated for fixed time intervals of $1 \mathrm{~min}, 5 \mathrm{~min}, 10 \mathrm{~min}$, and $30 \mathrm{~min}$. All moments and related quantities like turbulence intensities, wind vector, friction velocity $u_{*}$ (Fig. 3) or Monin-Obukhov length $L_{*}$ (Fig. 20)are calculated in the local Earth coordinate system (LEC) according to Sun [2007] and the so-called natural coordinate system ( $\mathrm{y}_{n}$-axis orthogonal to the $\mathrm{x}_{n}$-axis; $\mathrm{y}_{n}$-axis parallel to the Earth surface; $\mathrm{z}_{n}$-axis orthogonal on the $\mathrm{x}_{n}-\mathrm{y}_{n}$ plane). The sensible heat flux is determined by calibration of $T_{s}$ against the data obtained from ventilated psychrometers and the application of a procedure as described by Schotanus et al. [1983]. An extended ogive analysis [Oncley, 1989, Beier and Weber, 1992] was added as a quality test for the convergence of the covariance function and of $I_{S}$ for each time interval (see paper section 5.3.4) and also to compare with data obtained by Spirig et al. [2005]. Their spectral correction to the time series to introduce contributions from higher frequencies above $0.20 \mathrm{~Hz}$ to fluxes $\left(\overline{w^{\prime} \rho^{\prime}}{ }_{i}\right)$ of trace substances is not applied in our analysis because of the unknown spectral behaviour. Instead errors related to the separation of measuring volumes of sensors, 
their response time and the length of the sampling interval $\Delta$ were estimated as discussed in detail by Dlugi et al. [2010].

\section{Exchange Processes, Chemistry and Foot-Print}

\subsection{Structures of Wind Components, Temperature and Humidity}

In addition to the describtion of meteorological and chemical quantities at the measuring height $z=37 \mathrm{~m}$ (this is $7 \mathrm{~m}$ above mean canopy height $h_{c}=30 \mathrm{~m}$ ), we discuss observations of horizontal wind velocity $u_{H}$ (Fig. 3), vertical wind velocity $w$, air temperature $T$ and specific humidity $q$ (Fig. 2 ) from the complete profile measurements at the main tower between heights $z=2 \mathrm{~m}$ and $z=37 \mathrm{~m}$ on day 206, 2003 from 09:00 - 15:00 CET.

\subsubsection{Wind Components}

The vertical resolved measurements of micrometeorological quantities at the main tower and the west tower allow to present vertical structures in the wind velocity as function of of time. To compare with temperature structures from fast psychrometer measurements $(0.1 \mathrm{~Hz})$ the ten second averaged data from the sonic anemometers (Metek USA-1) are presented according to the measuring and calibration procedures as described here in section 1 and Fig. 9.

The horizontal wind velocity $u_{H}$ is mostly smaller than $1 \mathrm{~m} \mathrm{~s}^{-1}$ inside the canopy. Only occasionally $u_{H}$ values up to about $5.5 \mathrm{~m} \mathrm{~s}^{-1}$ are measured above canopy in the afternoon. The vertical velocity $w$ shows upward and downward directed motion with small or near zero values in between mostly with data in the range $-1 \mathrm{~ms}^{-1} \leq w \leq 1.5 \mathrm{~m} \mathrm{~s}^{-1}$. Only between 12:00 CET and 12:40 CET a strong downdraft related to convective clouds approach velocities up to $2.5 \mathrm{~ms}^{-1}$. Most downdrafts penetrate down to $z \approx 0.6 h_{c}$ or occasionally even below that height (Fig. $9-14$ ). The upward transport is visible over the complete time between 09:00 CET and 15:00 CET while downward transport becomes less pronounced after 13:40 CET when the atmosphere above the canopy becomes more stable as indicated by the MoninObukhov length $L_{*}$ (Fig. 20) and discussed already by Dlugi et al. [2010], although canopy air heated up during short events with high net radiation input (Fig. 1) with significant shifts to unstable conditions.

\subsubsection{Temperature and Humidity}

During the day, the air temperature (Fig. 2) increases throughout the vertical profile with the highest values in the upper canopy part (Fig. 11). The temperature maxima are related to preceding maxima in the net radiation with larger vertical gradients after 12:30 CET than before (Fig. 1). The specific humidity profile (Fig. 12) shows that upper canopy air dries over time while humidity maxima are observed mostly in the lower canopy air and are related to maxima in net radiation. Downward transported air is often drier than canopy air. This is especially visible for the strong downward directed transport between 12:30 CET and 12:40 CET (Fig. 12). The variability of the vertical temperature and humidity profiles is presented as deviations of $10 \mathrm{~s}$ averages from detrended means (Fig. 13, 14). In general, the variability of both quantities inside the canopy below $z=h_{c}=30 \mathrm{~m}$ is larger than above. But the observed structures of heating and cooling respectively drying or moistening extend from the lowest measuring level $(z=2 \mathrm{~m})$ up to heights above canopy and especially the measuring height $z=37 \mathrm{~m}$.

When we calculate $I_{S}$ as function of $\mathrm{OH}$ respectively $\mathrm{OH}_{\bmod }$ two data points at 10:40 CET and 13:30 CET remain outside the sector given by the dotted lines (section 4.2 and Fig. 4 in the paper).

The downward transport at 10:40 CET (Fig. 10) causes a simultaneous temperature (Fig. 13) and humidity (Fig. 14) decrease.

Especially the mixing ratio of isoprene which contribute to $I_{S}$ according to Eqs. 7, 8 becomes small in the downdraft: $c_{i}=0.3 \mathrm{ppb}$ (Fig. 6,8 ), $c_{j}=2.28 \cdot 10^{-4} \mathrm{ppb}$ and $c_{j_{m o d}}=1.57 \cdot 10^{-4} \mathrm{ppb}$ with the normalized standard deviations $\sigma_{i} / c_{i}=0.51, \sigma_{j} / c_{j}=0.26$ and the correlation coefficient $r_{i j}=-0.02$.

This results in the small value of $I_{S}=-0.003$ at 10:40 CET in downward transported air for the chemical situation with $f \approx 0.65$ (see section 3.3.2, Fig: 25 ) as discussed in section 4.2 .3 in the paper.

At 13:30 CET we found short periods with downdrafts and also updrafts resulting in an average value for vertical wind speed $w \approx 0$ with a temperature (Fig. 13) and humidity (Fig. 14) increase in and above canopy caused by the influence of net radiation (Fig. 1) on the canopy heating and evaporation. As discussed in section 4.2.2 this situation appears to be driven mainly by the chemical state of the system. 


\subsection{Advection}

The advection term in Eq. 5 in the paper may be written for the vertical divergences of the advective flux of any compound $c_{k}$ with mean wind velocity $\bar{w} \cdot \overline{c_{k}}$ and the turbulent flux $\overline{w^{\prime} \cdot c_{k}^{\prime}}$. The sum of the horizontal and vertical components of the divergence terms can be estimated from

a) the term of divergence of the mean flow field times the mean mixing ratio,

b) the spatial gradients of $\overline{c_{k}}$ times the corresponding mean velocity component,

c) the divergence of all tree components of the turbulent flux

The divergence of the mean flow field can be as large as $0.1 \mathrm{~s}^{-1}$ under the influence of tall vegetation and complex terrain [e.g. Sun, 2007, Stull, 1988].

For small mesoscale circulation [e.g. Stull, 1988] the divergence decreases to $10^{-3}-10^{-2} \mathrm{~s}^{-1}$ and should be multiplied by the mixing ratio $c_{i} \lesssim 1 \mathrm{ppb}$ for isoprene. Therefore the contribution of this term should be smaller than $10^{-2} \mathrm{ppbs}^{-1}$. The spatial gradients of isoprene (b) ) are determined from measurements by Spirig et al. [2005] and Schaub [2007]. The two horizontal terms are smaller then $10^{-3} \mathrm{ppb} \mathrm{m}^{-1}$ and the vertical term at the main tower is in the range $10^{-3}-10^{-2} \mathrm{ppb} \mathrm{s}^{-1}$. With $\overline{u_{H}}<2 \mathrm{~m} \mathrm{~s}^{-1}$ and $\bar{w}<0.3 \mathrm{~m} \mathrm{~s}^{-1}$ this results in about $2 \cdot 10^{-3} \mathrm{ppb} \mathrm{s}^{-1}$ for the horizontal term and less than $10^{-2} \mathrm{ppbs}^{-1}$ for the vertical term and is less than about $10^{-2} \mathrm{ppb} \mathrm{s}^{-1}$ for the total term in the order of magnitude estimation.

The divergence of the turbulent fluxes of isoprene can only be estimated from measurements done at this site during a short experiment before the ECHO 2003 campaign, when the inlets of two PTR-MS instruments were installed at $37 \mathrm{~m}$ and $26 \mathrm{~m}$ height at the main tower. The isoprene fluxes varied between $10^{-2}$ and $4 \cdot 10^{-2} \mathrm{ppb} \mathrm{m} \mathrm{s}^{-1}$ with vertical divergences in the range of $10^{-3} \mathrm{ppb} \mathrm{s}^{-1}-3 \cdot 10^{-3} \mathrm{ppb} \mathrm{s}^{-1}$. If we assume the same relation between fluxes and divergence for the horizontal divergence terms as for the vertical contribution, these terms are smaller than $4 \cdot 10^{-3} \mathrm{ppb} \mathrm{m} \mathrm{s}^{-1}$. This agrees to the calculation of the residuum of the flux divergence in Fig. 2 in the paper. In comparison to this residuum of $-5 \cdot 10^{-4}$ to $1.7 \cdot 10^{-3} \mathrm{ppb} \mathrm{s}^{-2}$, we may also conclude that our estimate of spatial gradients of $c_{i}$ is an upper limit for the conditions on day 206 at the main tower.

\subsection{Dependence on Wind Direction and Time}

\subsubsection{Introduction}

All quantities like mixing ratios and their statistical moments (mean, standard deviation, variance, skewness, kurtosis) depend on time by the influences of chemical and mixing processes in the flow and the interaction with emission sources surrounding the main tower (Fig. 1). The analysis of all data also yields several relations for the influences of chemical compounds on factor $f$ in Eq. (4) as discussed in section 2.3 in the paper. The influence of other compounds than isoprene on the mean reaction rate with $\mathrm{OH}$ and the fraction of isoprene reacting with $\mathrm{OH}$ is given in Table 3 in the paper. To find possible direct influences of sources of several reactants encluding isoprene on $f, \mathrm{OH}_{\text {mod }}$ or $I_{S}$, these quantities are presented as function of mean wind direction $D_{h}$. In addition, quantities influencing the magnitude of $I_{S}$ as function of $D_{h}$ like standard deviations and the correlation coefficient $r_{i j}$ are shown.

\subsubsection{The Factor $f$}

The mixing ratios of $\mathrm{NO}_{2}$ and $\mathrm{NO}$ decrease with increasing time (Table 2 in the paper) above canopy (Figs. 15, 16). The segregation intensity $I_{S}$ is not directly coupled to this decrease. The high $\mathrm{NO}_{\mathrm{x}}$ level caused low $\mathrm{O}_{3}$ mixing ratios in the morning which increase up to about $40 \mathrm{ppb}$ at 15:00 CET (Fig. 17 . The factor $f$ can only be calculated as average for time intervals of 1 hour or larger. It depends on wind direction and other factors (Fig. 25 here and Fig. 5 in the paper). Therefore if short time variations of reactants influences $f$ in a time interval such impacts on $\mathrm{OH}_{\text {mod }}$ can not be quantified based on observations. But the analysis of $I_{S}$ or $r_{i j}$ as function of the reaction rate shows that such deviation from the mean value of $f$ for the hourly time intervals are most likely.

The measured mixing ratios of isoprene increase from the wind sector West to South and to East with the exception of three data points (Fig. 18). The largest mean value of $c_{i}=1.57 \mathrm{ppb}$ is reached at 14:20 CET for $I_{S}=-0.096$ (Figs. 8 and 15). The two other data points are at 13:50 CET (1.08 ppb) and 12:20 CET (0.97 ppb). An estimation of the source area by a foot - print calculation for the momentum as well as the sensible heat flux [Horst, 1997] shows that these concentrations are measured during situations with unstable stratification $\left(L_{*}<0\right)$ when their sources are located near the main tower (Figs. 19, 20, 
21 ) in a distance below about $200 \mathrm{~m}$. For the purpose of simplicity only the results for the $75 \%$ and $90 \%$ cumulative presentation of the flux should be considered. The maxima of isoprene variance $\sigma_{i}$ are detected in the wind sector near South where also strong emitting oaks are located near the main tower.

The factor $f$ is influenced by several reactants and increases with time (Fig. 25) but reveals no dependence on wind direction (Fig. 22). Also the mixing ratios of $\mathrm{OH}$ and $\mathrm{OH}_{\text {mod }}$ show no dependence on wind direction $D_{h}$ (Figs. 23, 24). $\mathrm{OH}_{\text {mod }}$ reaches a maximum in the air of a downdraft around 12:30 CET (Fig. 10) just before the large downdraft near 12:35 CET. This maximum in $\mathrm{OH}_{\text {mod }}$ and also in $r_{i j}$ coincides with the maximum of $I_{S}$ (Fig. 26 here and Fig. 11 in the paper).

\subsubsection{Terms Influencing the Segregation Intensity $I_{S}$}

The segregation intensity $I_{S}$ can be expressed by the product of the normalized standard deviations times the correlation coefficient (Eqs. 7 and 8 in the paper). The mixing ratio $c_{i}$ and the standard deviation $\sigma_{i}$ of isoprene depend both on $D_{h}$ (Figs. 18, 27). For $\mathrm{OH}$ both quantities show no dependence on wind direction $D_{h}$ (Figs. 23, 24). But some maxima are found for the normalized standard deviations (Figs. 29, $30)$.

The maxima of segregation intensity $I_{S}$ is calculated when conditions with highest levels of buoyant production BP occur (Fig. 20 in the paper). This situation coincides with a dominant influence of nearby isoprene sources in the South - West sector together with maxima of normalized standard deviation of isoprene. The bouyancy production $B P$ is also characterized by $\bar{w}>0 \mathrm{~m} \mathrm{~s}^{-1}$ but the vertical velocity show stronger oscillations during such periods. Therefore in a short time interval transport in both directions is likely (Fig. 10). Bouyancy develops in the cloud topped boundary layer (CTBL) with time scales larger than $600 \mathrm{~s}$. We expect for a not completely developed CTBL for the conditions on day 206, 2003 that the normalized standard deviation of isoprene and $r_{i j}$ are not completely at its maximum especially for conditions at 14:20 CET. A comparison with results of the convective boundary layer (CBL) mixing concept by Vinuesa and Vilà-Guerau de Arellano [2003, 2005] shows that the computed normalized standard deviation for isoprene is always at least a factor of 2 larger than the experimental values. We therefore conclude that the boundary layer is in a non - equilibrium (instationary) state which results in a reduction of $-I_{S}$. An estimated value for a stationary state at 14:20 CET would be in the range $-0.27<I_{S}<-0.2$ for values computed with this CBL mixing concept.

A further aspect which should be mentioned is that our calculation of factor $f$ relies on a small variability of reactants during the hourly period. Schaub [2007] mentioned, that occasionally short time events with mixing ratios of $\mathrm{CO}$ from plumes crossing the forest site up to $340 \mathrm{ppb}$ are detected after 11:00 CET especially in the wind sector East to South. If such events also happened for time intervals at 12:50 CET, 13:30 CET and 14:20 CET, the calculated $\mathrm{OH}_{\bmod }$ is to large. As a consequence, the related data points in Fig. 7 in the paper must be shifted to the left along the abscissa. A short increase of $\mathrm{CO}$ from about $140 \mathrm{ppb}$ to about $300 \mathrm{ppb}$ reduces $f=0.75$ (point 1 in Fig.7) to $f=0.53$. This results in a shift of this data point to the left by a factor of 0.71 . If this correction is applied to three triangles in Fig. 7 in the paper, all these points are shifted to the left into the group of the other data points. For data point labelled $2, f=0.95$ would be reduced to $f=0.65$ with a comparable shift to the left. The same holds for data point labelled 3. Therefore especially for the relation given in Fig. 7 in the paper, also the potential short time variability of $f$ is an aspect which has to be considered for this interpretation of data. This aspect can be quantified only by higher time resolution of all chemical measurements than it was provided in our case.

\section{Terms of the Balance of Covariance}

\subsection{Estimation of Terms of the Balance Equation of the Covariance}

Here we give a further description on how the terms in Eq. 9 in the paper are calculated and quantities which could not be determined directly are estimated. During ECHO 2003 all components of the wind vector $\left(u_{k}\right)$ and the temperature $T$ were measured throughout the canopy $(30 \mathrm{~m})$ between $2 \mathrm{~m}$ and $41 \mathrm{~m}$ above ground in 9 heights with a time resolution of $10 \mathrm{~Hz}$ (chapter 2 and Dlugi et al. [2010]). In addition, 8 psychrometer with time resolution of about $0.066 \mathrm{~Hz}(15 \mathrm{~s})$ for temperature $T$ and specific humidity $q$ were installed at the same heights except $41 \mathrm{~m}$. Therefore first up to fourth moments of wind velocity components and temperature and their mixed moments (e.g. also third moments like $\overline{u_{k}^{\prime} u_{l}^{\prime} T^{\prime}}$ ) could be calculated. 
One can compare the terms of the interactions of the temperature - velocity field $\left(u_{k}, T\right)$ (and with less time resolution the humidity - velocity $\left(u_{k}, q\right)$ and temperature - humidity - field $\left.(T, q)\right)$ to the terms in Eq. (9), respectively Eq. (13), or Eq. (16) in the paper. This is done in a way that $q$ is replaced by isoprene and $\mathrm{T}$ by $\mathrm{OH}$. The compounds isoprene and $\mathrm{OH}$ could be only measured with higher time resolution at one height of $37 \mathrm{~m}$ ( $7 \mathrm{~m}$ above mean canopy height).

But vertical profiles for mean quantities with time resolution of about $180 \mathrm{~s}(\mathrm{OH})$ and $600 \mathrm{~s}$ (isoprene) are available from measurements of others as cited in section 2 of the paper and by Dlugi et al. [2010]. Therefore the vertical gradients of time integrated mean values of $u_{k}, T, q$ and isoprene (ISO) as well as $\mathrm{OH}$ are available for the calculation of the mixed terms with spatial gradients. In addition the covariances (fluxes) for momentum, heat, humidity and isoprene as well as $\mathrm{OH}$ could be directly calculated from the measured data. The results for isoprene, $\mathrm{OH}, \mathrm{HO}_{2}$ and heat are also presented in the same reference [Dlugi et al., 2010] together with covariances between $T$ or the sonic temperature $T_{s}$ and mixing ratios e.g. of $\mathrm{OH}$, isoprene and $\mathrm{HO}_{2}$. This gives some more insight into the influences of transport and emission of BVOCs on $\mathrm{OH}$ mixing ratio at the measuring height.

We often find small negative values of $\overline{T_{s}^{\prime} c_{j}^{\prime}}\left(\overline{T_{s}^{\prime} \mathrm{OH}^{\prime}}\right)$ together with small positive values of $\overline{T_{s}^{\prime} c_{i}^{\prime}}$ $\left(\overline{T_{s}^{\prime} \mathrm{ISO}^{\prime}}\right)$ or $\overline{T_{s}^{\prime} \mathrm{HO}_{2}^{\prime}}$ (Fig. 9 in Dlugi et al. [2010]).

This indicates - for example - that warm canopy surfaces tend to emit isoprene which immediately reacts with $\mathrm{OH}$ causing a negative correlation between $T_{s}$ ( or $T$ ) and $\mathrm{OH}$. This is also shown by the result that a positive (- upward directed - ) sensible heat flux is observed together with negative (downward directed) local fluxes of $\mathrm{OH}$. The $\mathrm{OH}$ - fluxes are only caused by the chemical reactions with isoprene and other compounds (Tables 2 and 3 in the paper). To estimate this influence, we used the factor $f$ in terms of $\mathrm{OH}$ - reaction with isoprene versus $\mathrm{OH}$ - reaction with all others (measured) reactants (Eq. (4) in the paper).

The magnitude of terms $T P I_{k}, T P O H_{k}$ and $A_{1 k}$ in Eq. 9 in the paper is directly estimated from measured data. This estimate is given in Table 4 of the paper together with the directly calculated values for term $S$. We also found empirically that the percentage change in vertical gradients of $T, q$, ISO and $\mathrm{OH}$ in the height interval above $23 \mathrm{~m}$ around canopy top $\left(z=h_{c}=30 \mathrm{~m}\right)$ is comparable within $28 \%$ during that experimental period. Therefore vertical profiles (and relative changes of local gradients) are comparable. All scalar quantities show maxima inside the canopy in the range $0.77<z / h_{c}<1$ and decrease with increasing height above canopy. Therefore the signs of the mean gradients are the same. The influences of horizontal gradients of $T, q, u_{k}$ and ISO are estimated from additional measurements at the two towers aligned along mean main wind direction. Results from one of them - the west-tower [see Spirig et al., 2005] - describe also the diurnal behavior of isoprene fluxes. $\mathrm{OH}$ is controlled only by chemical reactions on a local scale of some $m^{3}$ as also discussed in Dlugi et al. [2010]. Therefore the horizontal gradient of $\mathrm{OH}$ is purely determined by the horizontal gradients of mixing ratios of chemical compounds acting as sources and sinks as given in the paper in Eq. (1). We found empirically $\delta \overline{c_{l}} / \delta x_{k} \approx a_{l} \cdot \sigma_{j}\left(\Delta x_{k}\right)^{-1}$ with $\Delta x_{k}=3 \mathrm{~m}$ for all reactants (Index l) including isoprene. $\sigma_{j}=\sigma_{O H}$ is given in our Fig. 6 in the paper. Therefore the calculated mean local vertical gradient of $\mathrm{OH}$ of about $3 \cdot 10^{-5} \mathrm{ppb} \mathrm{m}^{-1}$ is larger than the mean horizontal gradient of about $1 \cdot 10^{-5} \mathrm{ppb} \mathrm{m}^{-1}$ but still is of the same order of magnitude.

Consequently, in $T P I_{k}$ the horizontal gradient has to be multiplied by the horizontal component of the turbulent flux of isoprene which is smaller by one order of magnitude than the vertical component. Therefore, within an uncertainty of less than $10 \%$, only the vertical contribution remains for term $T P I_{k}$, e.g. $\mathrm{TPI}_{3}(\mathrm{k}=3)$. For term $\mathrm{TPOH}_{k}$ the calculated vertical turbulent flux of $\mathrm{OH}$ is about a factor of 3 larger than the horizontal contribution and the total sum is - therefore - less than $4 \cdot 10^{-5} \mathrm{ppb} \mathrm{m}^{-1}$. To obtain the $\mathrm{OH}$ - flux all three terms are added. Finally we obtain $T P I_{k} \simeq T P I_{3} \simeq T P O H_{k}$ (see Table 4 in the paper). The discussion on the advection of covariance $A_{1 k}$ by the influence of the divergence of the mean flow field is shortly described in section 5 of the paper. But the term advection of covariance with the mean flow $A_{2 k}$ needs further discussion. As mentioned in our paper we find by the data analysis that $R_{i j} \simeq R E S$ can only be fulfilled together with $S \approx 0$ if also the horizontal derivatives in $A_{2 k}$ contribute to $R E S$ respectively to $R E$ or to $R E_{i s}$. This is further discussed in the following section 4.2 and 4.3 and the order of magnitude of the resulting term is given in brackets $\left(10^{-4} \mathrm{ppb}^{2} \mathrm{~s}^{-1}\right)$ in Table 4 in the paper.

The mean error given in the Table 4 in the paper is larger for triple products than for second order terms like covariances. The spatial derivatives of these quantities are estimated according to mixed moments composed of fluctuations of specific humidity $q$ and temperature $T$ (second moments) and $u_{k}$, $q$ and $T$ (third moments). For the error analysis, we replaced $T$ by $\mathrm{OH}$ and $q$ by isoprene. By the measurements presented, we could assure that the spatial derivatives are the comparable. For the error analysis of $A_{1 k}$ and $A_{2 k}$ the relative errors of $q$ and $T$ are replaced by those of $\mathrm{OH}$ and isoprene. The same holds for term $T T_{k}$. This allows to estimate the influence of different processes on the covariance 
$\operatorname{cov}(\mathrm{ISO}, \mathrm{OH})$ and $I_{S}$ by an order of magnitude estimation (Section 5.2 in the paper). As mentioned before, the finding $R E S \simeq R_{i j}$ (Eq.13 in the paper) is only possible if the horizontal gradients in $A_{2 k}$ significantly contribute to the magnitude of this term (see Table 4 in the paper, number in brackets).

The dominant term in $R_{i j}$ is the normalized variance of isoprene. This term has a mean error of only 7\%. The second term $\mathrm{CH}_{i s}$ is dominated by term IV3 from Eq. 10 in the paper. This triple correlation has a mean error of about $64 \%$, but contributes only by about $10-15 \%$ to the budget of $I_{S}$ in Eq. 16 in the paper. Therefore the mean error of $R_{i j}$ is only $16 \%$ (see Table 4 in the paper). The term $C_{i j}$ is composed only of third order terms. The numerical values for these terms have very different orders of magnitude (Tab. 4 in the paper), and, therefore, only terms III3 and IV3 contribute to the numerical values resulting in Eq. (10) or finally in Eq.(16) in the paper. To summarize, the spatial derivatives are calculated in analogy to those from correlations between the fields of velocity, humidity and temperature. The moments itself and their errors are calculated from measurements on velocity, isoprene and OH. This is an estimation based purely on observations and the application of balance equations [Stull, 1988]. We proceed according to common practice to replace trace gases by surrogates as $T$ or $q$ in higher moments and their derivatives.

\subsection{Empirical Relations}

The analysis of data from ECHO 2003 shows that the amount of the intensity of segregation $\left(-I_{S}\right)$ for the reaction between isoprene and $\mathrm{OH}$ increases with increasing $\mathrm{OH}_{\text {mod }}$ (Fig. 4 in the paper). For an estimation of $I_{S}$ a linear approximation yields $I_{S}=-320\left[\mathrm{ppb}^{-1}\right] \cdot \overline{\mathrm{OH}}_{m o d}[\mathrm{ppb}]$. Therefore, doubling the mixing ratio $\mathrm{OH}_{\text {mod }}$ also doubles $I_{S}$ in the range $4 \cdot 10^{-5} \leq \mathrm{OH}_{\text {mod }} \leq 4 \cdot 10^{-4} \mathrm{ppb}$.

Often measurements are performed which cannot be used to estimate the influence of other chemical compounds than isoprene on $\mathrm{OH}$ removal.

Then $f$ (Eq. 4 in the paper) cannot be estimated and $\mathrm{OH}_{\text {mod }}$ is unknown. But with measured $\mathrm{OH}$, $\left|R_{i j}\right|$ may be estimated in the linear relation to $\overline{\mathrm{OH}} \cdot \operatorname{var}(\mathrm{ISO})$ (Fig.31). $\left|R_{i j}\right|$ also shows a high correlation, but larger scatter, with $\sigma_{i}$ (Fig.32).

If only data points for "common conditions" (section 5.3.2 in the paper) are considered on the right side of Fig. 14 in the paper one can estimate the magnitude of $I_{S}$ for a more completely characterized system by $I_{S} \approx 1100\left|R_{i j_{m o d}}\right|$ even if $\left|R_{i j_{m o d}}\right|$ is replaced by $R_{i j} \approx 2 \cdot \overline{\mathrm{OH}} / \overline{I S O} \cdot \operatorname{var}($ ISO) as shown in Fig. 31. Based on this data set the magnitude of $I_{S}$ does not "vary simply much like the magnitude of the isoprene variance but with opposite sign" [Davis, 1992], as cited also by Patton et al. [2001] and applied by their "simple formulation" for their model study. The relation is modified by nvar(ISO) ${ }_{i s}$ and is not the only factor of influence as given by Eq. (16) in the paper, which will be further discussed in the following.

This finding from Fig.31 also agrees qualitatively with the basic assumptions made to calculate segregation intensity by LES by Patton et al. [2001]. They found $I_{S}$ (and $R_{i j}$ ) being proportional to $\sigma_{i}$, but, contrary to the analysis of field data from ECHO 2003, $-r_{\text {ISO.OH }}>0.8$ was established while experimental data from ECHO 2003 point towards $-r_{\text {ISO }} \mathrm{OH}<0.55$ but may be too low as discussed in section 4.2.5 in the paper. The magnitude of the correlation coefficient increases with increasing mean reaction rate.

Note, a correlation coefficient $-r_{i j}>0.8$ would shift $I_{S}$ towards the maximum values around $I_{S} \approx$ -0.2 to -0.25 as applied by Pugh et al. [2011] in their analysis.

\subsection{Comparison of Reaction Terms and the Sum of Transport Terms}

The storage term in the balance of the covariance (Eq. (12), Fig. 11 in the paper) is shown to be small compared to terms which compose $R_{i j}$. Therefore Eq. (15) in the paper can be formulated as a diagnostic equation for the covariance to analyze the contributions of term three on the right side being the variance of isoprene times the quotient of mean mixing ratios of $\overline{\mathrm{OH}}$ and isoprene for each 10 minute interval. The other chemical term $k_{i j} \cdot C_{i j}$ (divided by the isoprene mixing ratio times $k_{i j}$ ) reduces this contribution to the covariance by about $15 \%$ or less. The residuum $R E S$ summarises the net effect of turbulent interaction and advection (Eq. (12) in the paper) and must be also divided by the same factor as $k_{i j} \cdot C_{i j}$. This term is called $R E$ in Eq. (15) in the paper.

The different contributions of terms of Eq. (15) and in Figs. 15,16 in the paper show that $\overline{\mathrm{OH}} / \overline{\mathrm{ISO}}$. $\operatorname{var}$ (ISO) largely dominates the behavior of the covariance, because $R E$ is a residuum and mathematically serves to close the balance of covariance. Both terms, $\overline{\mathrm{OH}} / \overline{\mathrm{ISO}} \cdot \operatorname{var}(\mathrm{ISO})$ and $R E$, are larger by about one order of magnitude than the other two terms. A relation between $k_{i j} \cdot \overline{\mathrm{OH}} / \overline{\mathrm{ISO}} \cdot \operatorname{var}(\mathrm{ISO})$ and $R E S$ can also be found, because $S=0$, and, therefore, $R E S=R_{i j}$ in Eq.(15) in the paper and in Fig.33 here. 
The three marked points belong to the results obtained at 11:50 CET $\left(R E S=-2.73 \cdot 10^{-4} \mathrm{ppb}^{2} \mathrm{~s}^{-1}\right)$, 12:00 CET $\left(R E S=-1.78 \cdot 10^{-4} \mathrm{ppb}^{2} \mathrm{~s}^{-1}\right)$ and 14:20 CET $\left(R E S=-2.4 \cdot 10^{-4} \mathrm{ppb}^{2} \mathrm{~s}^{-1}\right)$ with dynamic and turbulent conditions different from other time intervals. As discussed in sections 5.3.4 and 4.2.4 in the paper the apparent intensity of segregation is $I_{S} \simeq 0$ at 11:50 CET, but with the correction discussed, $I_{S} \geq-0.06$ is most reliable. $I_{S}$ increases to about -0.13 at 12:00 CET and $I_{S}=-0.097$ at 14:20 CET with both ogives completely valid for the case of inhomogeneous mixing as for 12:30 CET (Fig. 17 in the paper).

As mentioned above, the maxima of $I_{S}$ are found when $\mathrm{NO}_{\mathrm{x}}$ and CO-mixing ratios (Table 2 in the paper) decrease and unstable conditions develop above canopy after 11:30 CET until about 13:00 CET and again around 14:10 CET. The period around 12:00 CET is characterized by a vertical downdraft with $-0.06 \leq \bar{w} \leq-0.14 \mathrm{~m} \mathrm{~s}^{-1}$ and a mean Monin - Obukhov length $L_{*}=-55 \mathrm{~m}$. Therefore mean reaction conditions are influenced by the chemical mixture (Table 2 and 3 in the paper) as well as by advective and convective transport rather than only by locally produced turbulence. The data point for 14:10 CET is for unstable conditions with $u_{*}=0.45 \mathrm{~m} \mathrm{~s}^{-1}$ (Fig. 3) and $L_{*}=-70 \mathrm{~m}$ (Fig. 20) within a period with neutral to stable stratification before and after that time interval as given also in section 3. In all cases with $I_{S}>-0.04$ turbulent kinetic energy (TKE) as well as buoyant production $(B P)$ [Stull, 1988] becomes larger showing again that non-local transport (convection) and mixing may have influenced segregation intensity as discussed in section 6.2 of the paper.

A tendency is observed that for increasing $k_{i j} \cdot \overline{\mathrm{OH}} / \overline{\mathrm{ISO}} \cdot \operatorname{var}(\mathrm{ISO})$ the term $R E S$ seems to be limited by a maximum of about $67 \%$ for line a) and $85 \%$ for the mean (line b) (Fig.33). Another approximation is obtained with $R E S=\left|R_{i j}\right|=-a \cdot k_{i j} \cdot \overline{\mathrm{OH}} / \overline{\mathrm{ISO}} \cdot \operatorname{var}(\mathrm{ISO})$. The normalization does not modify this relation, and, therefore, this behaviour is even more obvious (Fig.34) if both sides of Eq. (15) in the paper are divided by the product of the mean mixing ratios of isoprene and $\mathrm{OH}$ to obtain the diagnostic equation for the intensity of segregation $I_{S}$, Eq. (16) in the paper. The two terms are $R E_{i s}$ and $n v a r(\mathrm{ISO})_{i s}$. Their difference determines $I_{S}$ because the remaining chemical terms $C H_{i s}$ and $I_{S}$ in Eq. (16) are smaller (Figs. 15 and 16 in the paper) but causes the scatter around the mean of the curve in (Fig. 34). Therefore in the time behavior an increase of $\operatorname{nvar}(\mathrm{ISO})_{i s}-R E_{i s}$ is always related to an increase of the amount of $-I_{S}$ and vice versa (Fig. 16 in the paper).

Note, the three critical points discussed before (Fig.33) are not outside all other data points in Fig. 34. As before, the red circle is for the corrected value of $I_{S}$ (see section. 5.3.4 in the paper) and the other circles are for time intervals at 12:00 CET and 14:10 CET.

The intensity of segregation $I_{S}$ increases with increasing difference of both terms (Fig. 34), but the increase of $R E_{i s}$, as it is for $R E S$ (Fig. 33), is limited. Also the normalized variance of isoprene and the standard deviation $\sigma_{i}$ (Fig. 6 in the paper) have an upper bound. If - in addition - data from the ECHO field study also by Spirig et al. [2005] are considered - at least at this site - the difference term in Fig.34 should not exceed a value of 0.3 . This agrees with an uppermost value of about $I_{S} \lesssim-0.20$ from the data of this field study if the correlation coefficient would approach values $r_{i j} \gtrsim-0.7$. From Fig. 34 one may also conclude that the net effect of all terms in $R E_{i s}$ is to reduce the correlation between $I_{S}$ and nvar (ISO) $)_{i s}$.

A linear regression between $I_{S}$ and the difference of both terms leads to

$$
I_{S}=-0.67\left(\operatorname{var}(\mathrm{ISO})_{i s}-R E_{i s}\right)-0.0023
$$

with a correlation coefficient of $R=-0.92$. This linear anticorrelation is also reflected in the time behavior of these quantities in Fig. 16 of the paper because transport and mixing processes as well as the chemical system itself (Tables 2 and 3 ) influence $I_{S}$.

The chemical term $\sigma_{i}^{2}$ (and so $n v a r\left(\mathrm{ISO}_{i s}\right)$ ) is also directly modified by the reaction conditions at the main tower which are given by the quotient between the mean mixing ratios $\overline{\mathrm{OH}} /(\overline{\mathrm{ISO}}+\overline{\mathrm{OH}}) \simeq \overline{\mathrm{OH}} / \overline{\mathrm{ISO}}$ in Eq. (15) of the paper. This quotient increases with increasing variance $\sigma_{i}^{2}$, but should be limited for these measured field data which show $\mathrm{OH} / \mathrm{ISO}<5 \cdot 10^{-4}$ (Fig. 6 in the paper) with modifications according to Table 3 .

Without direct measurements of these quantities composing the terms in Eqs. (15 and 16) and the direct determination of $I_{S}$ (and $C_{i j}$ ) it is only possible to roughly estimate the potential magnitude of $I_{S}$ but not to understand the variability of segregation in this complex chemical system.

\section{Summary}

In addition to the discussion in the paper we present specific information on the field site, the way the measurements were performed and the analysis of chemical and micrometeorological quantities. This 
includes presentations on measured quantities like mixing ratios of $\mathrm{OH}$, isoprene and other compounds with their variability. In addition the fluctuations of micrometeorological parameter are given. The dependence on wind direction was discussed. The foot print analysis confirms results from Spirig et al. [2005] and Aubrun et al. [2005] and shows that in our case emissions of isoprene originate from trees in distances less than $200 \mathrm{~m}$ from the main tower. The maxima of intensity of segregation coincides with emissions of isoprene from nearby sources (oaks) during situations with largest values of bouyancy production. Additional material is presented for the estimation of terms of Eq. (9) in the paper to support the finding that the horizontal advection terms in $A_{2 k}$ significantly contribute to the balance.

In addition, the comparison of the reaction terms with the sum of transport terms allows to find some empirical relations to estimate the segregation intensity if only limited information is available from the field.

\section{References}

C. Ammann, C. Spirig, A. Neftel, Steinbacher M., M. Komenda, and A. Schaub. Application of PTR-MS for measurements of biogenic VOC in a deciduous forest. Int. J. Mass Spectrom., 239:87-101, 2004.

S. Aubrun, R. Koppmann, B. Leitl, M. Möllmann-Coers, and A. Schaub. Physical modelling of a complex forest area in a wind tunnel - comparison with field data. Agr. Forest. Meteorol., 129:121-135, 2005.

N. Beier and M. Weber. Turbulente Austauschprozesse in der Grenzschicht. Technical report, Meteorologisches Institut, Universität München, Germany, 1992.

B. Bohn. Solar spectral actinic flux and photolysis frequency measurements in a deciduous forest. $J$. Geophys. Res., 111:D15303, 2006. doi: 10.1029/2005JD006902.

R. Bohn, B.and Koppmann and F. Rohrer. Seasonal variations and profile measurements of photolysis frequencies $\mathrm{j}\left(\mathrm{O}^{1} \mathrm{D}\right)$ and $\mathrm{j}\left(\mathrm{NO}_{2}\right)$ at the ECHO forest field site. J. Geophys. Res., 111:D12303, 2006. doi: 10.1029/2005JD006856.

K. Davis. Surface fluxes of trace gases derived from convective profiles. PhD thesis, Univ. of Colorado, Boulder, 1992.

R. Dlugi, M. Berger, M. Zelger, A. Hofzumahaus, M. Siese, F. Holland, A. Wisthaler, W. Grabmer, A. Hansel, R. Koppmann, G. Kramm, M. Möllmann Coers, and A. Knaps. Turbulent exchange and segregation of $\mathrm{HO}_{\mathrm{x}}$ radicals and volatile organic compounds above a deciduous forest. Atmos. Chem. Phys., 10:6215-6235, 2010. doi: doi:10.5194/acp-10-6215-2010.

D. K. Farmer, P. J. Wooldridge, and R. C. Cohen. Application of thermal-dissociation laser induced fluorescence (TD-LIF) to measurement of $\mathrm{HNO}_{3}$, Ealkyl nitrates, $\sum$ peroxy nitrates, and $\mathrm{NO}_{2}$ fluxes using eddy covariance. Atmos. Chem. Phys., 6:3471-3486, 2006.

Th. Foken, R. Dlugi, and G. Kramm. On the determination of dry deposition and emission of gaseous compounds at the biosphere-atmosphere interface. Meteorol. Z., 4(NF):91-118, 1995.

A. Hofzumahaus, U. Aschmutat, M. Hessling, F. Holland, and D. H. Ehhalt. The measurement of tropospheric $\mathrm{OH}$ radicals by laser-induced fluorescence spectroscopy during the POPCORN field campaign. Geophys. Res. Lett., 23:2541-2544, 1996.

F. Holland, M. Hessling, and A. Hofzumahaus. Insitu measurement of tropospheric OH radicals by laser-induced fluorescence - a description of the KFA instrument. J. Atmos. Sci., 52(19):3393-3401, 1995.

F. Holland, A. Hofzumahaus, J. Schäfer, A. Kraus, and H.-W. Pätz. Measurements of OH and $\mathrm{HO}_{2}$ radical concentrations and photolysis frequencies during BERLIOZ. J. Geophys. Res., 108(D4a):8246, 2003. doi: 10.1029/2001JD001393.

T. W. Horst. A simple formula for attenuation of eddy fluxes with first-order-response scalar sensors. Bound.-Lay. Meteorol., 82:219-233, 1997.

S. P. Oncley. Flux Parameterization Techniques in the Atmospheric Surface Layer. PhD thesis, University of California, Irvine, CA, USA, 1989. 
E.G. Patton, K.J. Davis, M.C. Barth, and P. P. Sullivan. Decaying scalars emitted by a forest canopy: A numerical study. Boundary Layer Meteorol., 100:91-129, 2001.

T.A.M. Pugh, A.R. MacKenzie, B. Langford, E. Nemitz, P.K. Misztal, and C.N. Hewitt. The influence of small scale variations in isoprene concentrations on atmospheric chemistry over a tropical rain forest. Atmos. Chem. Phys., 11:4121 - 4134, 2011.

L. Sachs and J. Hedderich. Angewandte Statistik. Springer, Berlin, Heidelberg, New York, 2006.

A. Schaub. Untersuchung von Isopren und dessen Oxidationsprodukten in und oberhalb eines Mischwaldes. $\mathrm{PhD}$ thesis, Mathematisch-Naturwissenschaftliche Fakultät, Universität Köln, Germany, 2007.

P. Schotanus, F. T. M. Nieuwstadt, and H. A. R. de Bruin. Temperature measurements with a sonic anemometer and its application to heat and moisture flux. Bound.-Lay. Meteorol., 26:81-93, 1983.

C. Spirig, A. Neftel, C. Ammann, J. Dommen, W. Grabmer, A. Thielmann, A. Schaub, J. Beauchamp, A. Wisthaler, and A. Hansel. Eddy covariance flux measurements of biogenic VOCs during ECHO 2003 using proton transfer reaction mass spectrometry. Atmos. Chem. Phys., 5:465-481, 2005.

R. B. Stull. An Introduction to Boundary Layer Meteorology (Atmospheric Sciences Library). Springer, 1988. ISBN 9789027727688.

J. Sun. Tilt correction over complex terrain and their implication for $\mathrm{CO}_{2}$-transport. Boundary Layer Meteorol., 124:143-159, 2007.

J.-F. Vinuesa and J. Vilà-Guerau de Arellano. Fluxes and (co-)variances of reactiong scalars in the convective boundary layer. Tellus, 5B:935-949, 2003.

J.-F. Vinuesa and J. Vilà-Guerau de Arellano. Introducing effective reaction rates to account for the inefficient mixing of the convective boundary layer. Atmos. Environ., 39:445-461, 2005. 


\section{$6 \quad$ Figures}

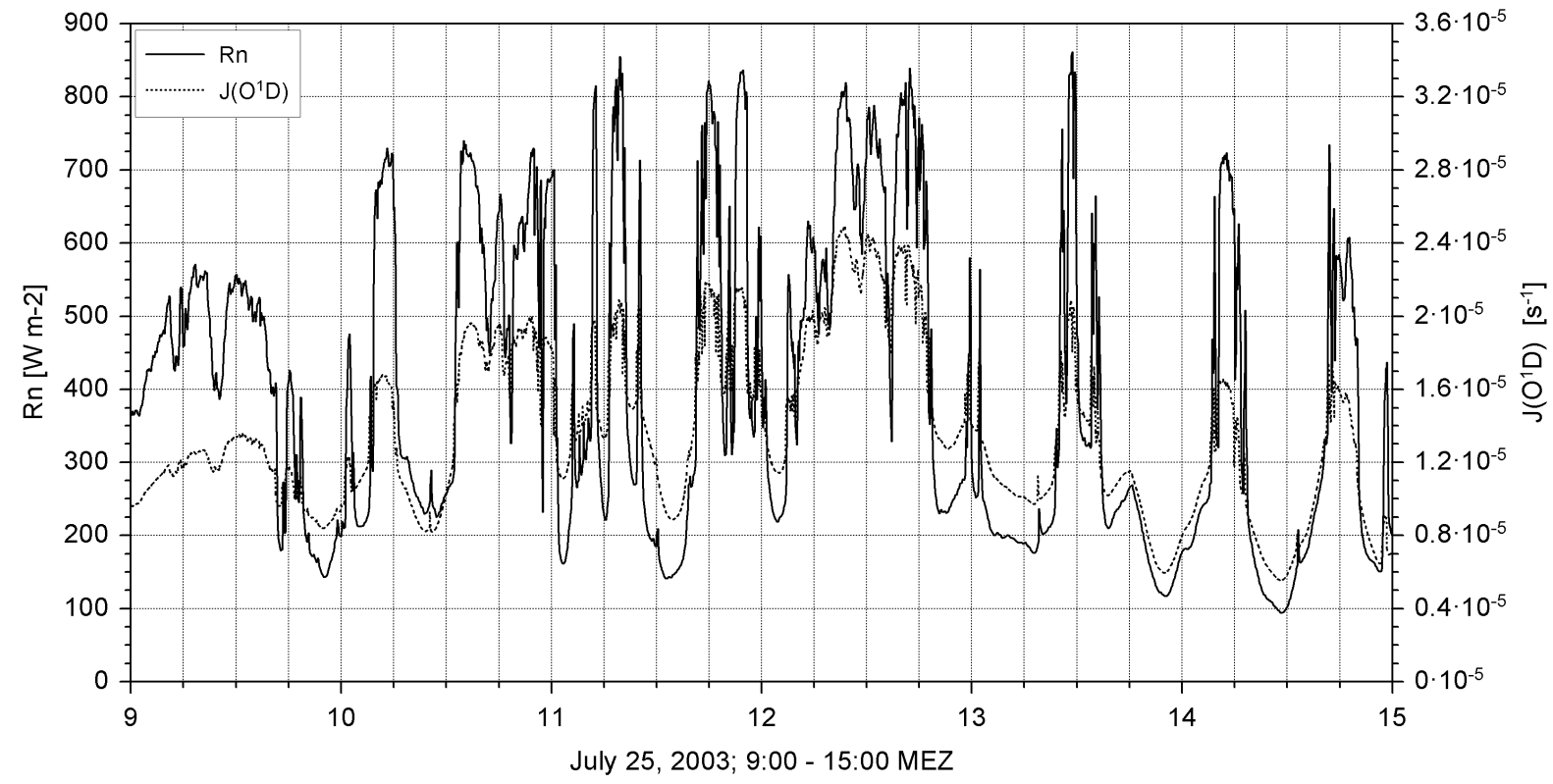

Figure 1: Net radiation $R n\left(\mathrm{Wm}^{-2}\right)$ and $J\left(\mathrm{O}^{1} \mathrm{D}\right)$ - photolysis frequency $\left(\mathrm{s}^{-1}\right)$ for 25 July 2003, 09:0015:00 CET (=MEZ) above canopy (From Dlugi et al. [2010]).

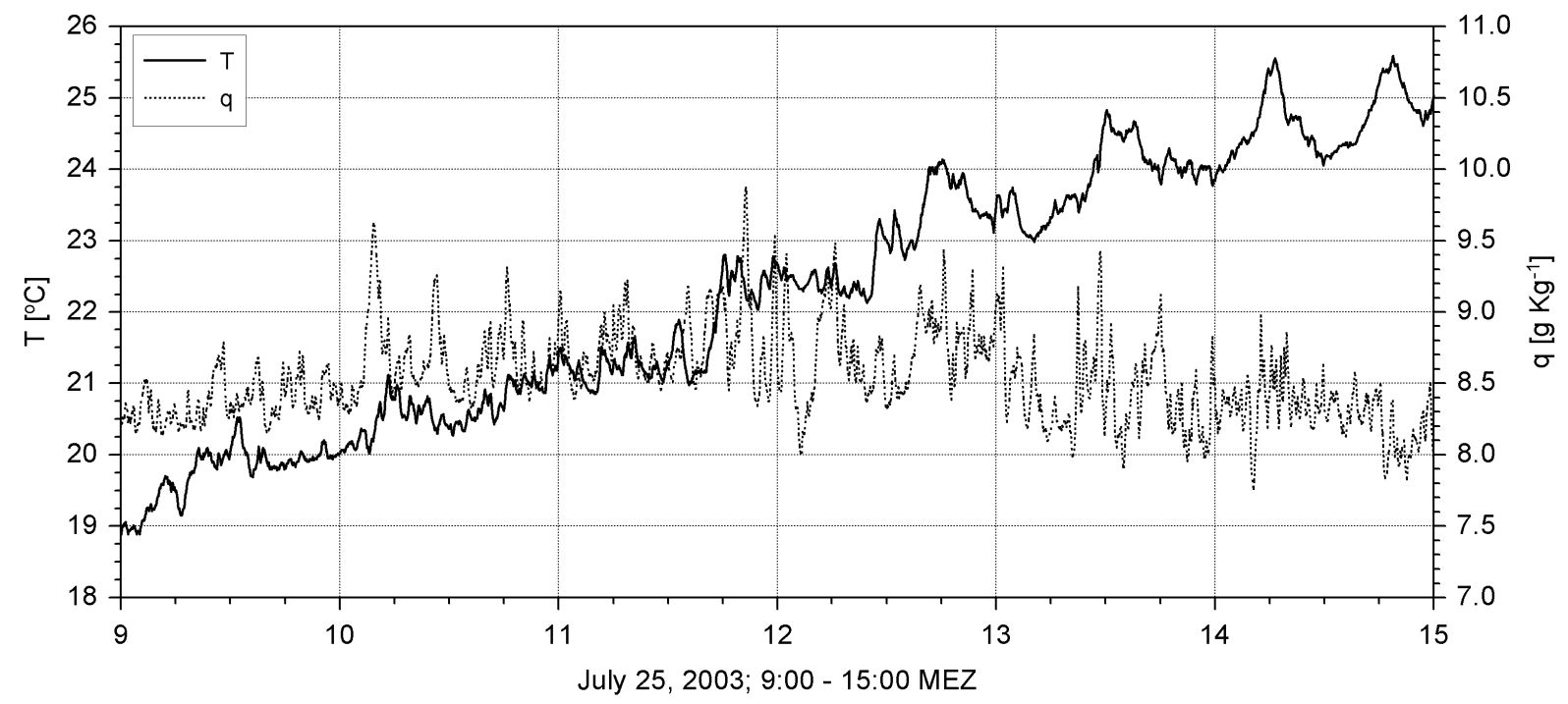

Figure 2: Air temperature $T\left({ }^{\circ} \mathrm{C}\right)$ and specific humidity $q\left(\mathrm{~g}_{\mathrm{H}_{2} \mathrm{O}} / \mathrm{kg}_{\mathrm{Air}}\right)$ from psychrometer at $37 \mathrm{~m}$ height for 25 July 2003, 09:00-15:00 CET (From Dlugi et al. [2010]). 


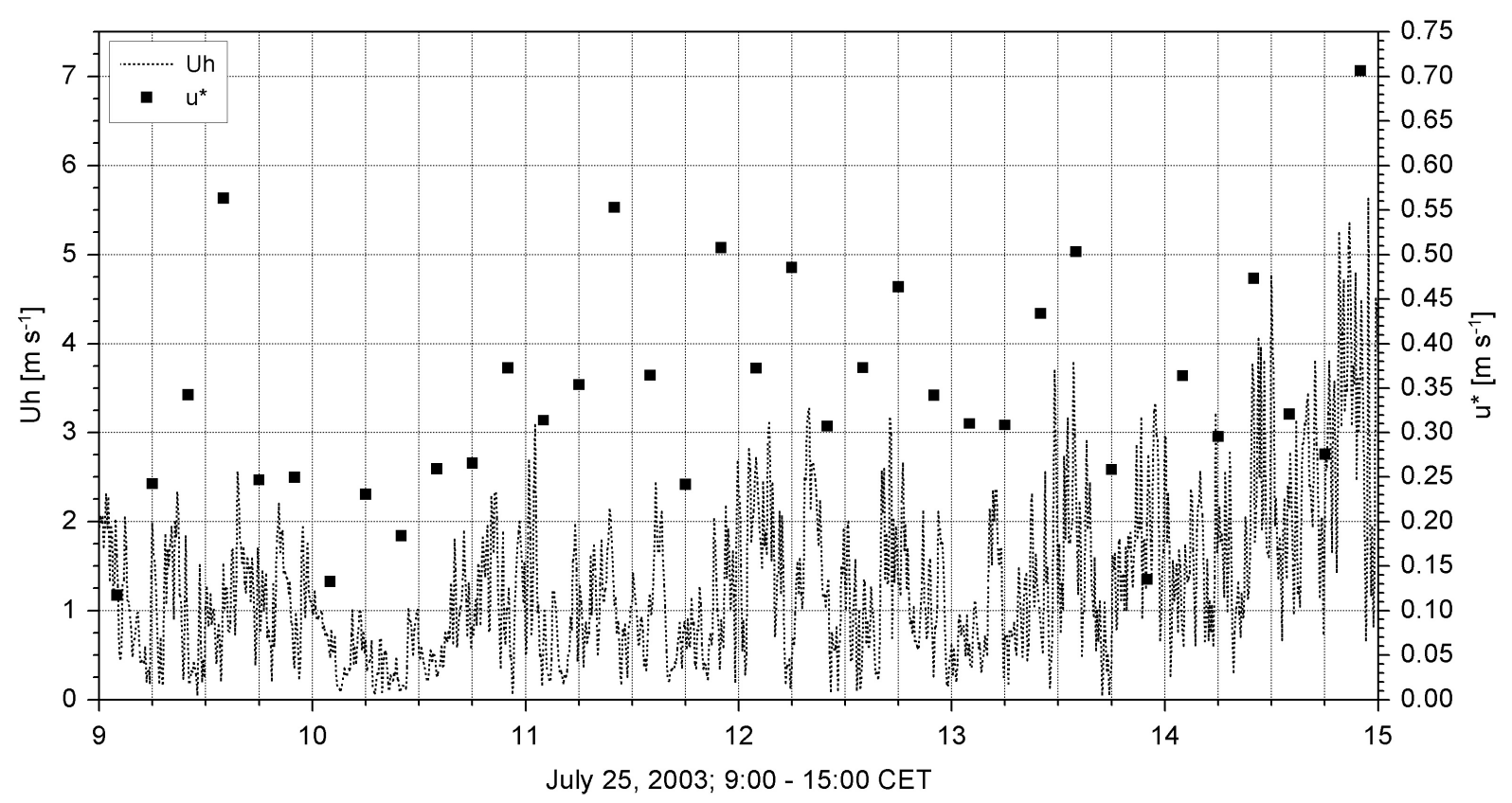

Figure 3: Horizontal wind velocity $U h\left(\mathrm{~ms}^{-1}\right)$ and friction velocity $\left(10 \mathrm{~min}\right.$ mean) $u *\left(\mathrm{~ms}^{-1}\right)$ at $37 \mathrm{~m}$ height for 25 July 2003, 09:00-15:00 CET (=MEZ) (From Dlugi et al. [2010]).

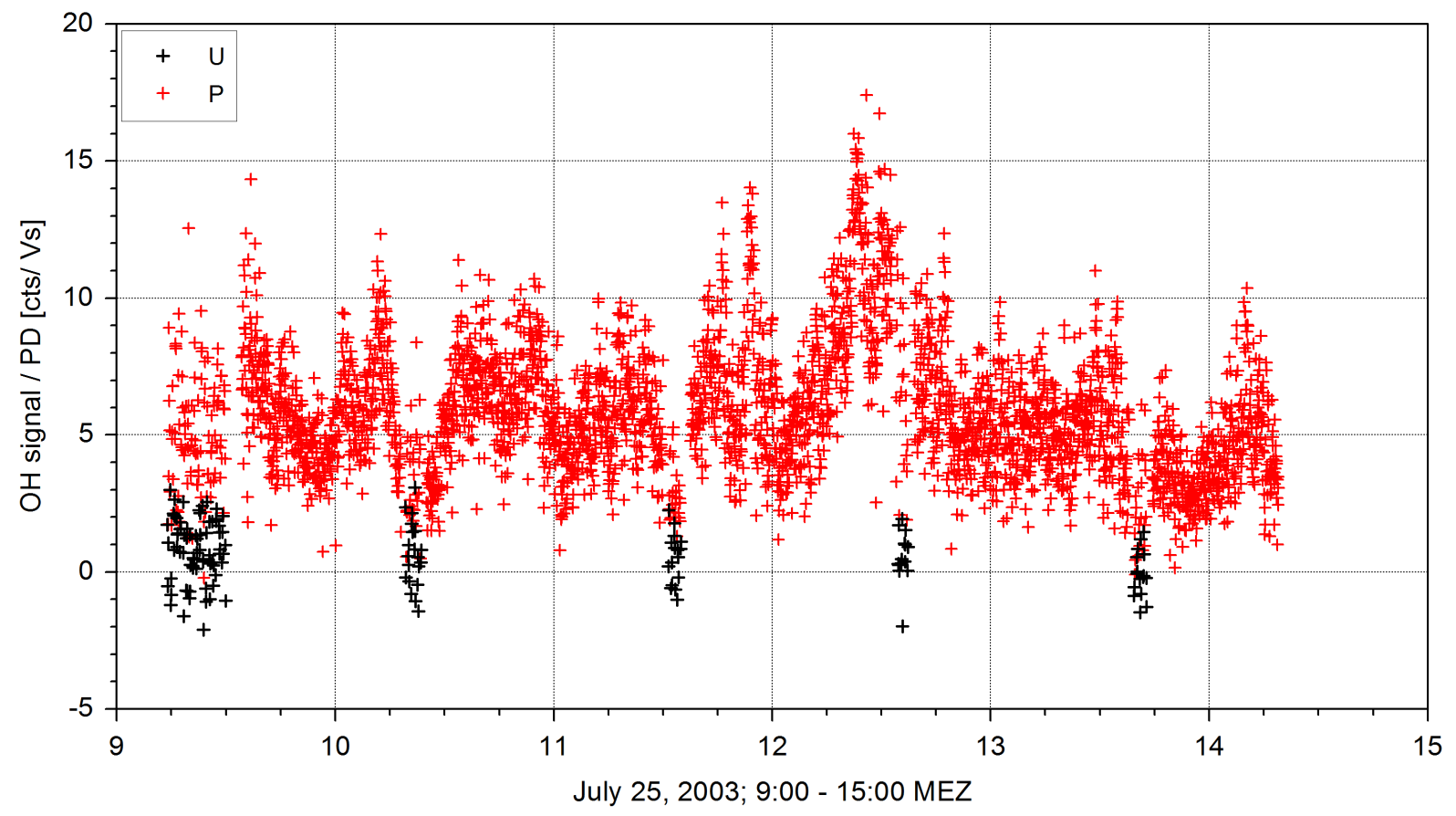

Figure 4: On (P) and off (U) resonance signals (cts/Vs) for $\mathrm{OH}$ (upper panel) and $\mathrm{HO}_{\mathrm{x}}$ (lower panel) measured by LIF on 25 July 2003 at $37 \mathrm{~m}$ height above ground (From Dlugi et al. [2010]). 


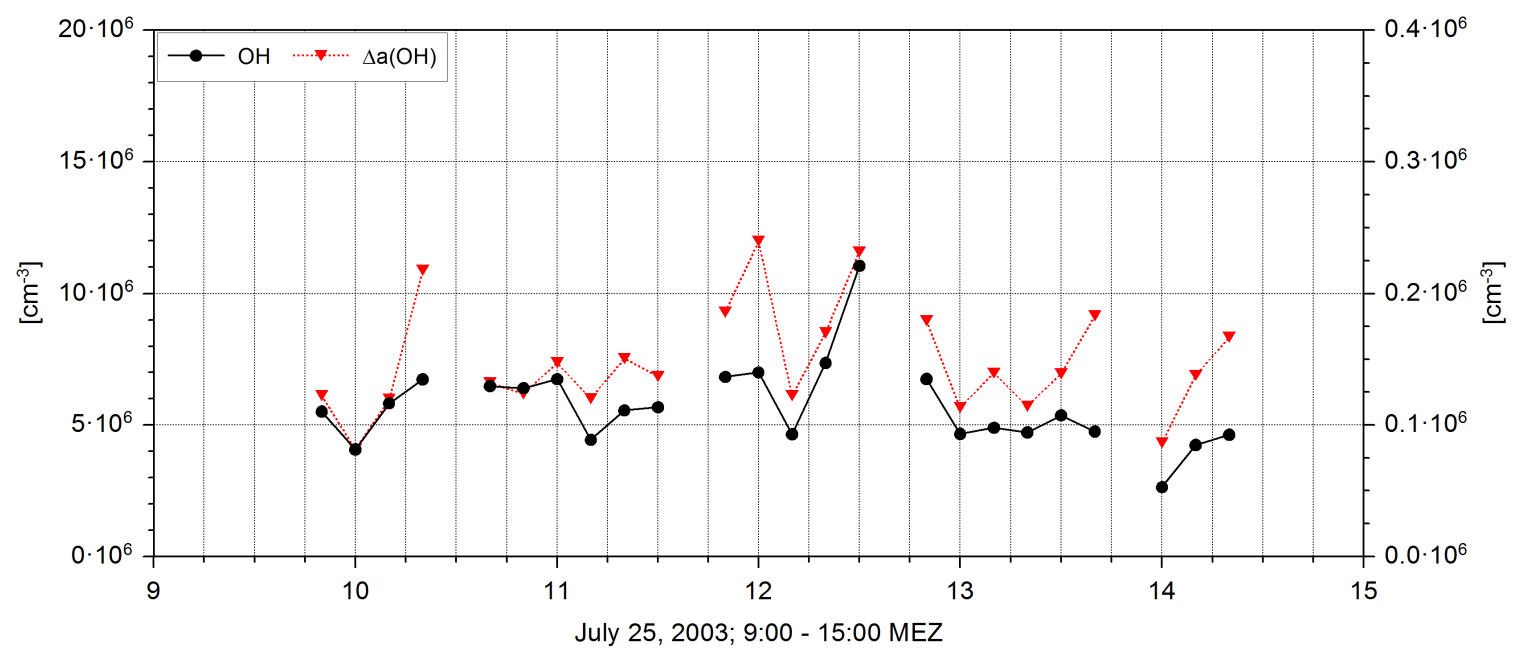

Figure 5: Mean concentration of $\mathrm{OH}\left(\mathrm{cm}^{-3}\right)$ and the standard error $\Delta a$ (right ordinate), measured at $37 \mathrm{~m}$ height by LIF on 25 July 2003, 09:00-15:00 CET (=MEZ) (Adapted from Dlugi et al. [2010]).

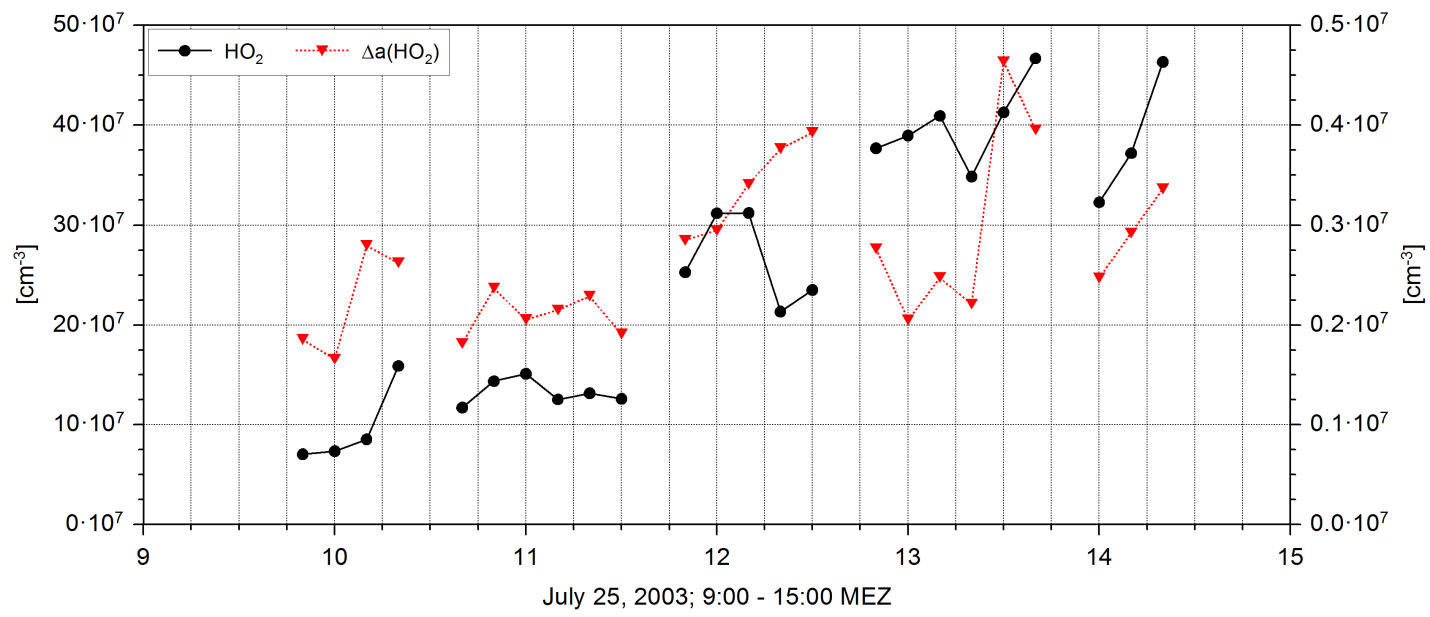

Figure 6: Mean concentration of $\mathrm{HO}_{2}\left(\mathrm{~cm}^{-3}\right)$ and the standard error $\Delta a$ (right ordinate), measured at $37 \mathrm{~m}$ height by LIF on 25 July 2003, 09:00-15:00 CET (=MEZ) (Adapted from Dlugi et al. [2010]).

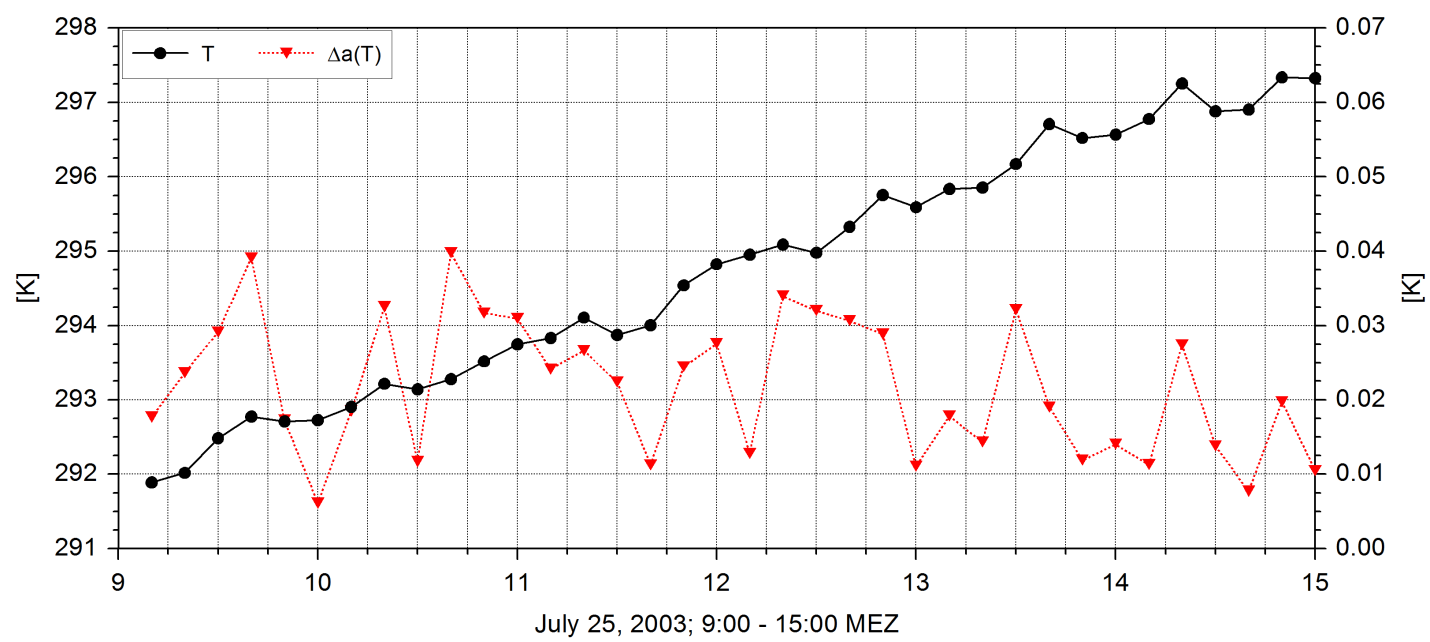

Figure 7: Mean value of temperature $T(\mathrm{~K})$ and the standard error $\Delta a$ (right ordinate), at $37 \mathrm{~m}$ height from a sonic anemometer for 25 July 2003, 09:00-15:00 CET (=MEZ) (Adapted from Dlugi et al. [2010]). 


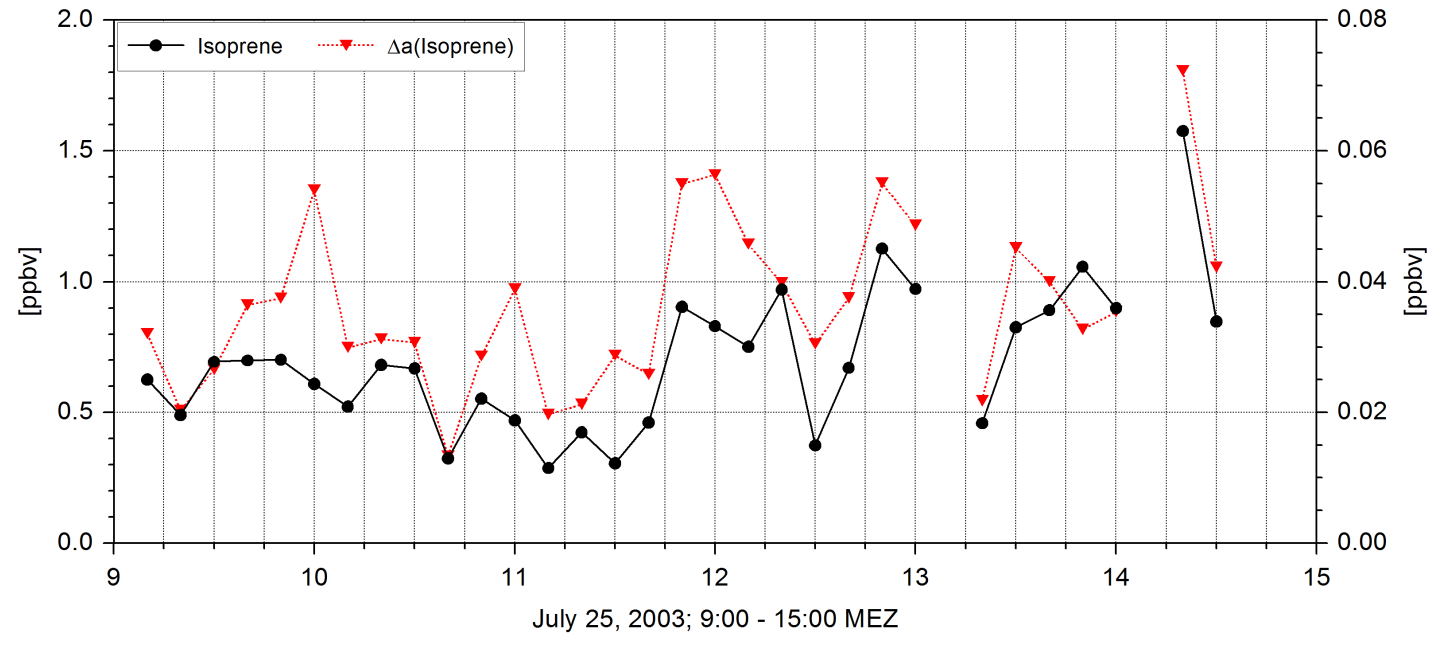

Figure 8: Mean mixing ratio of isoprene (ppbv) and the standard error $\Delta a$ (right ordinate), measured at $37 \mathrm{~m}$ height by PTR-MS on 25 July 2003, 09:00-15:00 CET (=MEZ) (Adapted from Dlugi et al. [2010]).

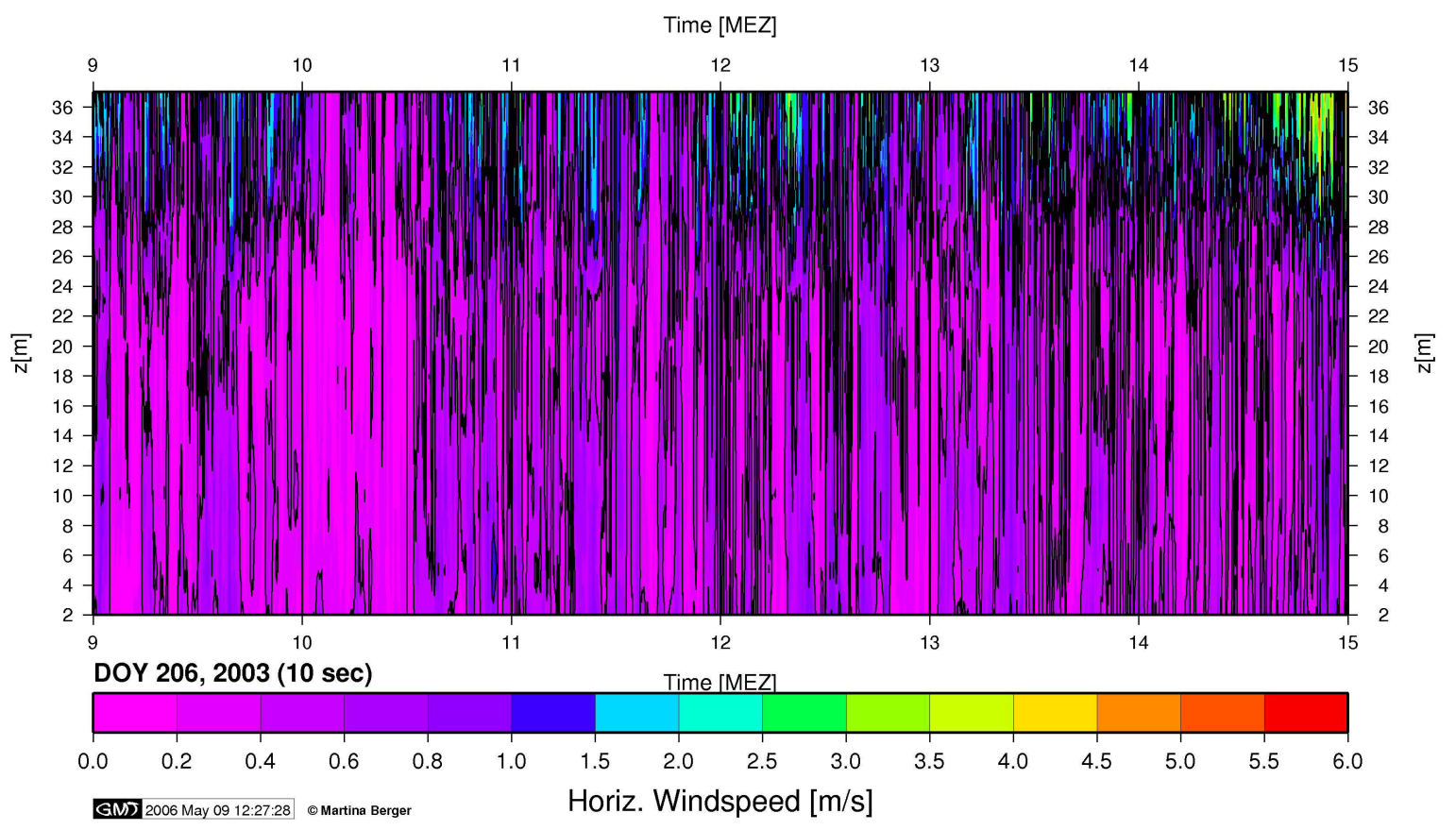

Figure 9: Vertical profiles of $10 \mathrm{~s}$ - averaged horizontal wind velocity as function of time at the main tower on 25 July 2003, 09:00-15:00 CET (=MEZ). 


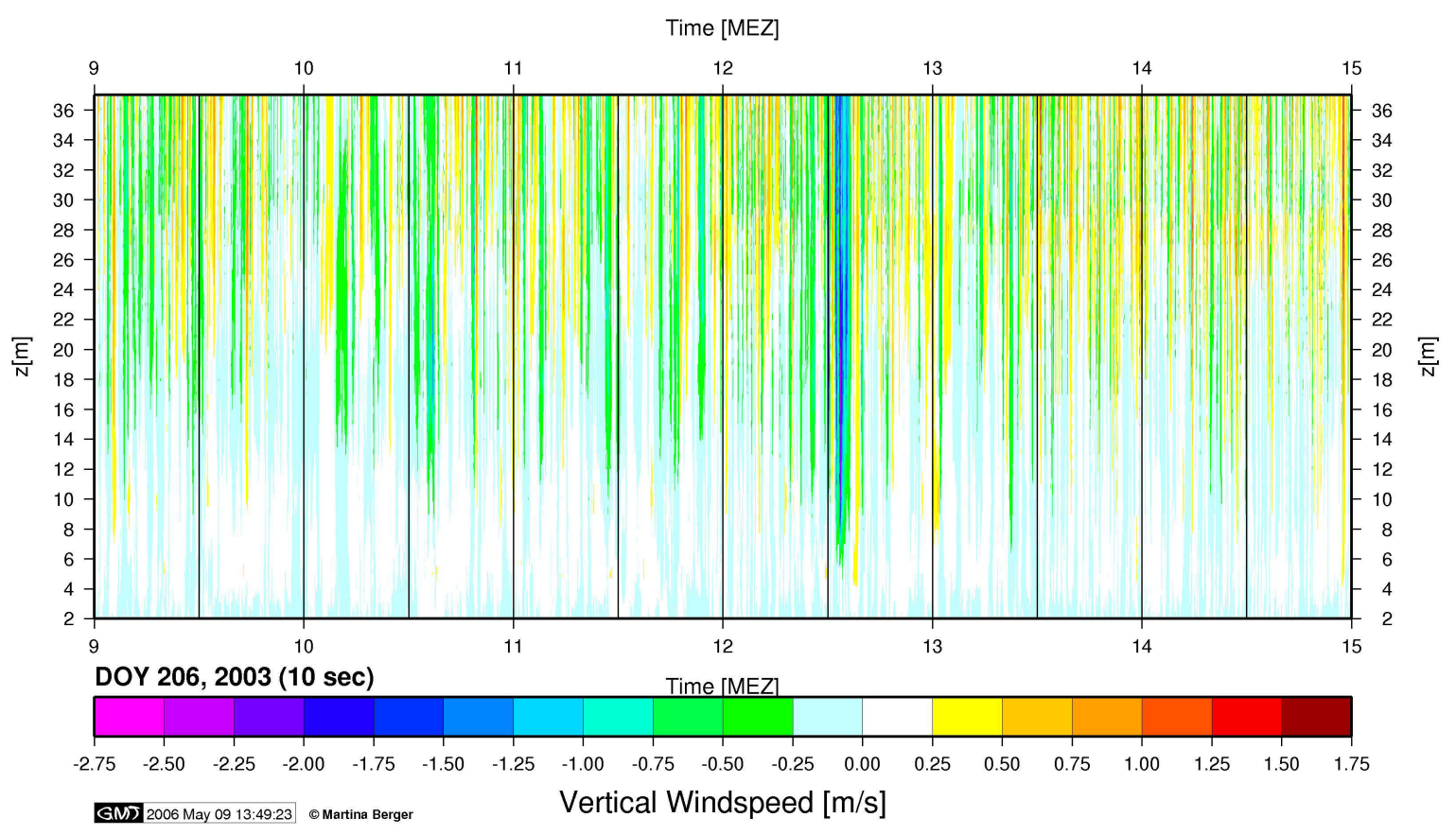

Figure 10: Vertical profiles of $10 \mathrm{~s}$ - averaged vertical wind velocity as function of time at the main tower on 25 July 2003, 09:00-15:00 CET (=MEZ).

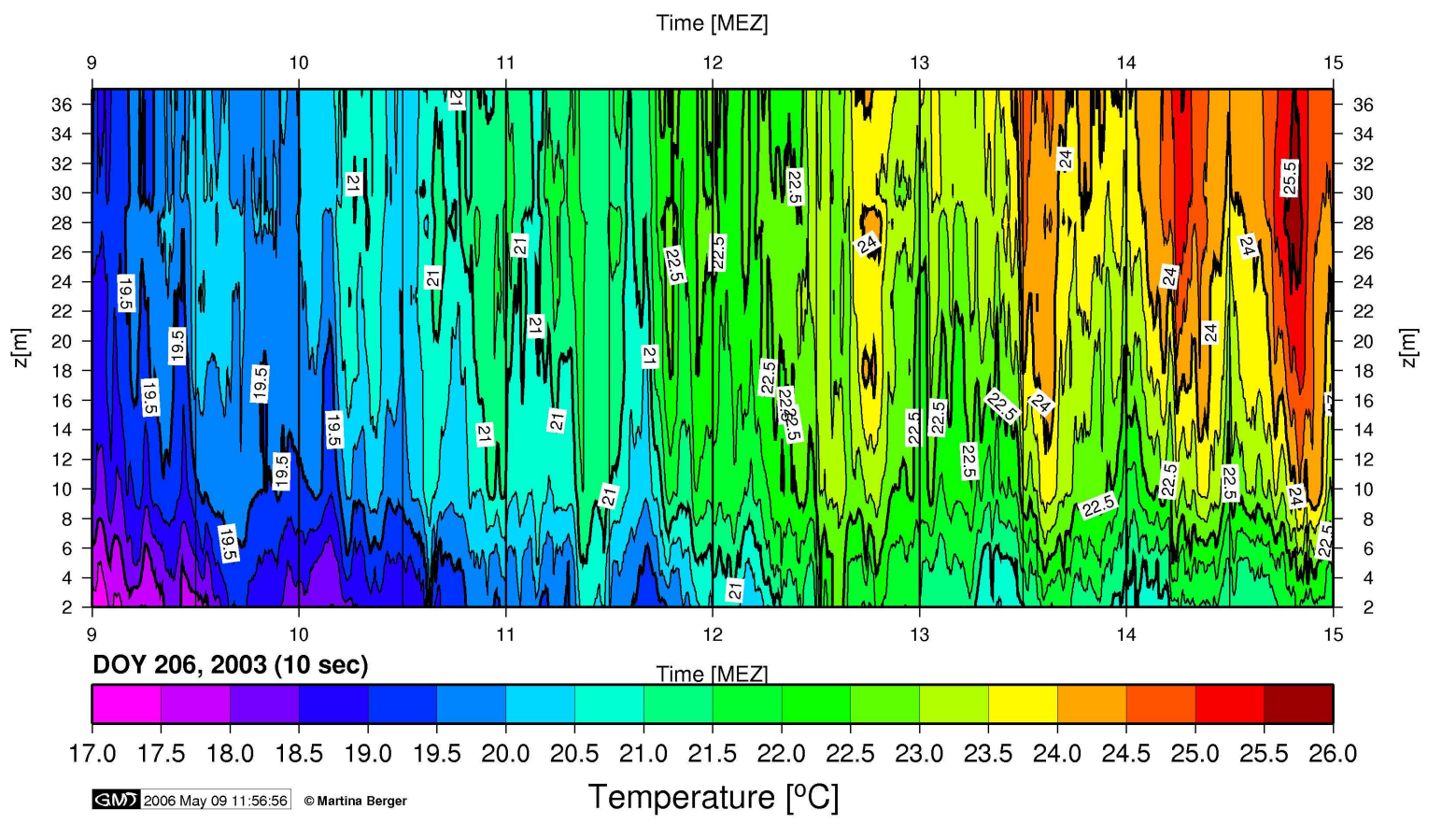

Figure 11: Vertical profiles of $10 \mathrm{~s}$ - averaged air temperature as function of time at the main tower on 25 July 2003, 09:00-15:00 CET (=MEZ). 


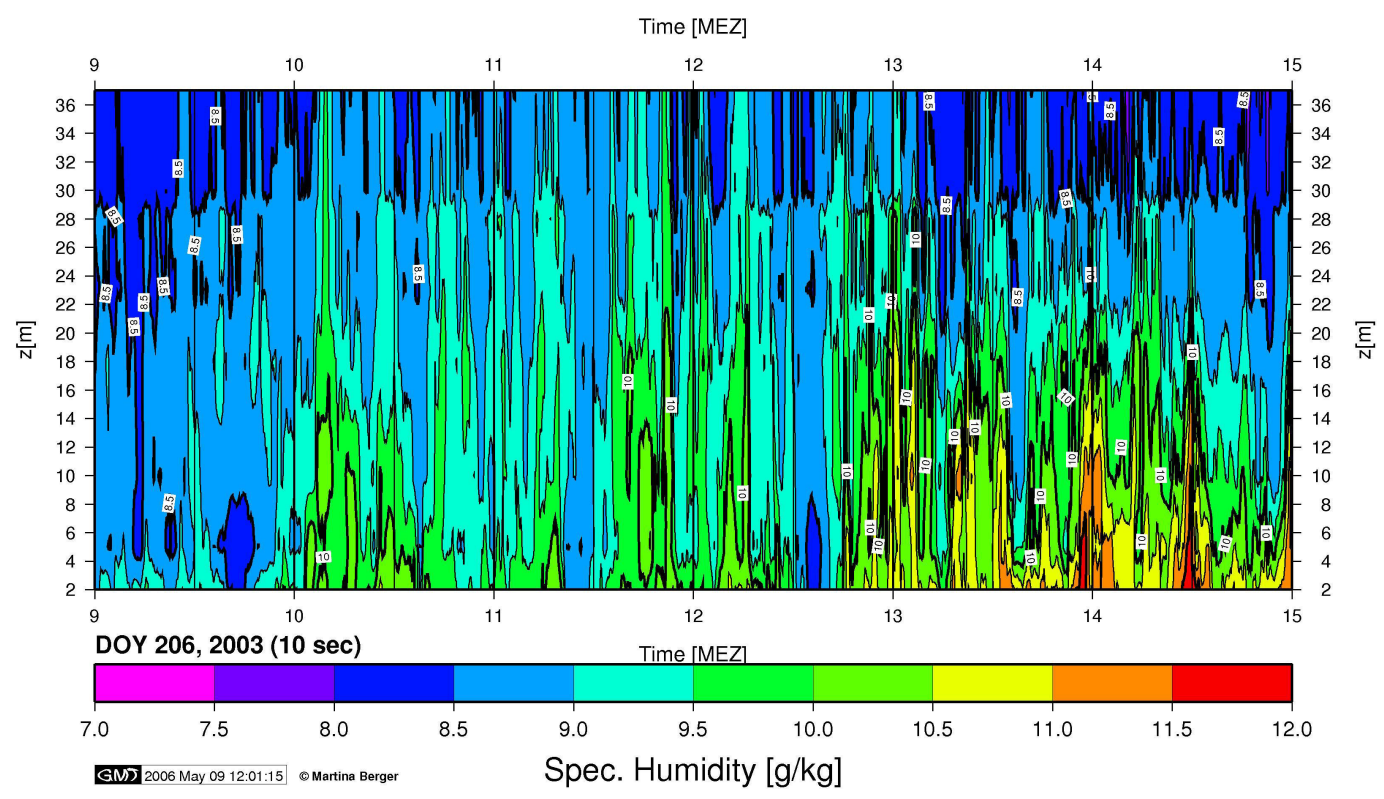

Figure 12: Vertical profiles of $10 \mathrm{~s}$ - averaged specific humidity as function of time at the main tower on 25 July 2003, 09:00-15:00 CET (=MEZ).

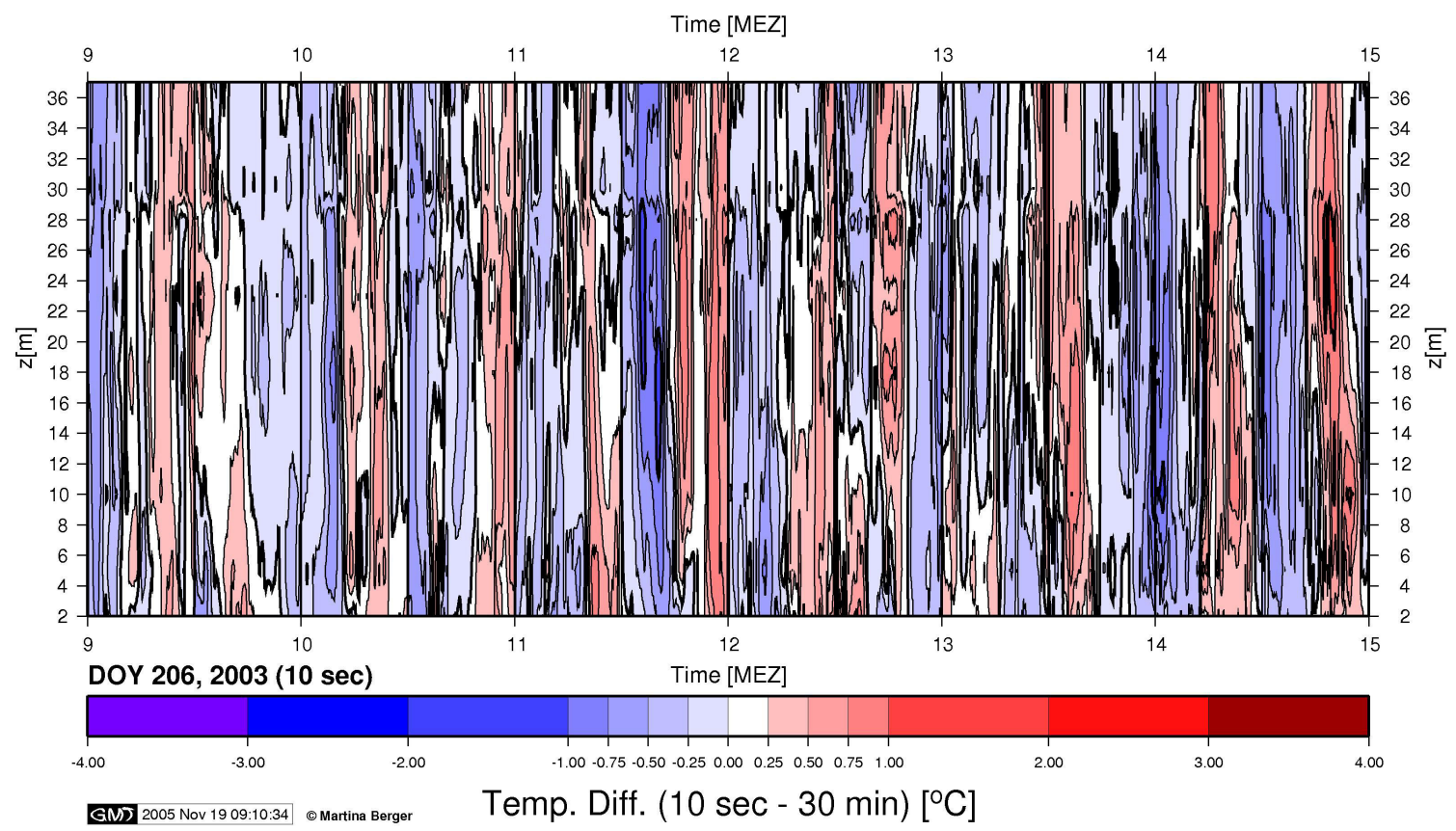

Figure 13: Vertical profiles of deviation of $10 \mathrm{~s}$ - averaged temperature from half hourly means as function of time at the main tower on 25 July 2003, 09:00-15:00 CET (=MEZ). 


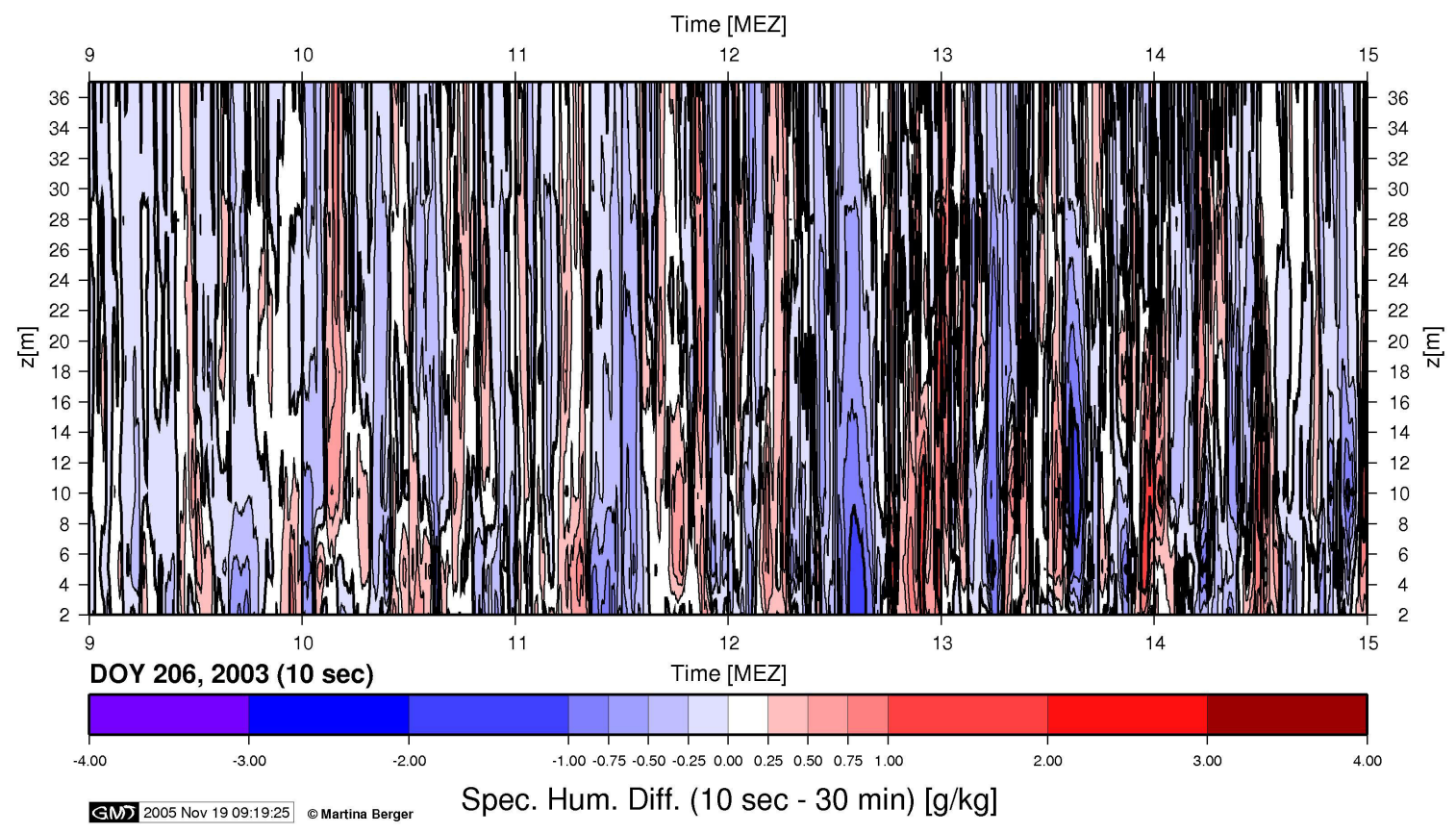

Figure 14: Vertical profiles of deviation of $10 \mathrm{~s}$ - averaged specific humidity from half hourly means as function of time at the main tower on 25 July 2003, 09:00-15:00 CET (=MEZ).

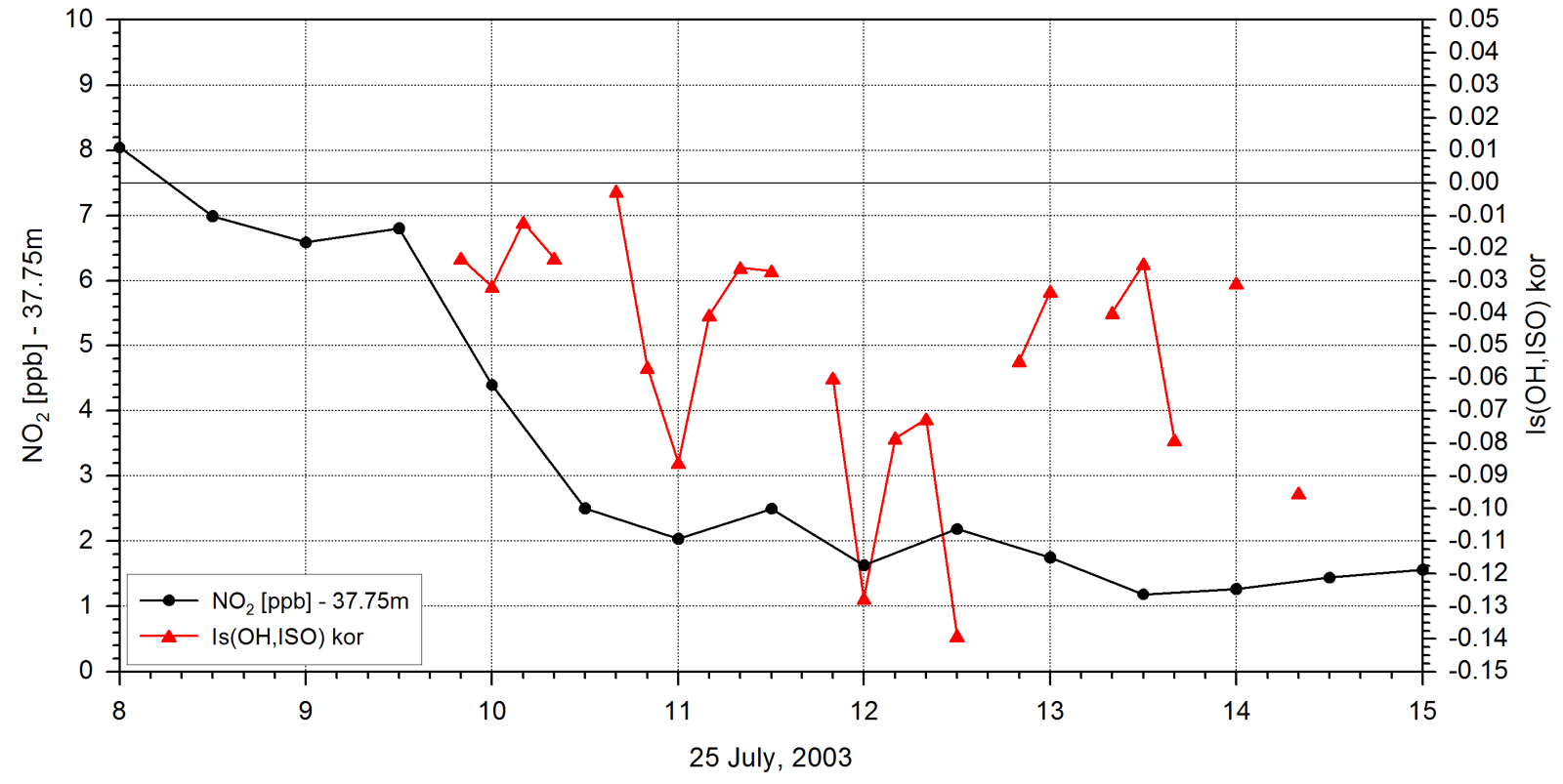

Figure 15: Mixing ratio of $\mathrm{NO}_{2}$ and $I_{S}$ as function of time at the main tower on 25 July 2003, 09:0015:00 CET. 


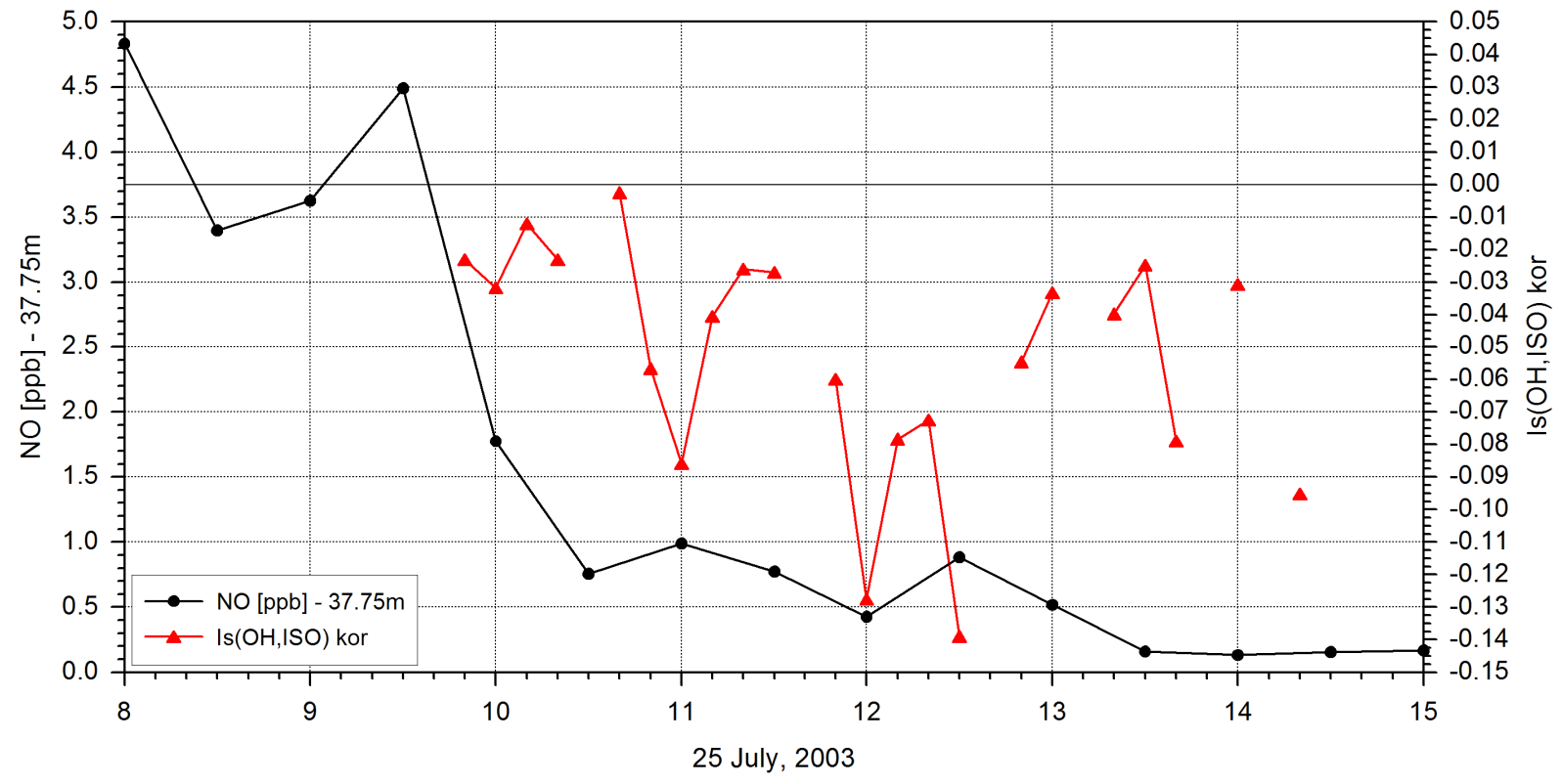

Figure 16: Mixing ratio of $\mathrm{NO}$ and $I_{S}$ as function of time at the main tower on 25 July 2003, 09:0015:00 CET.

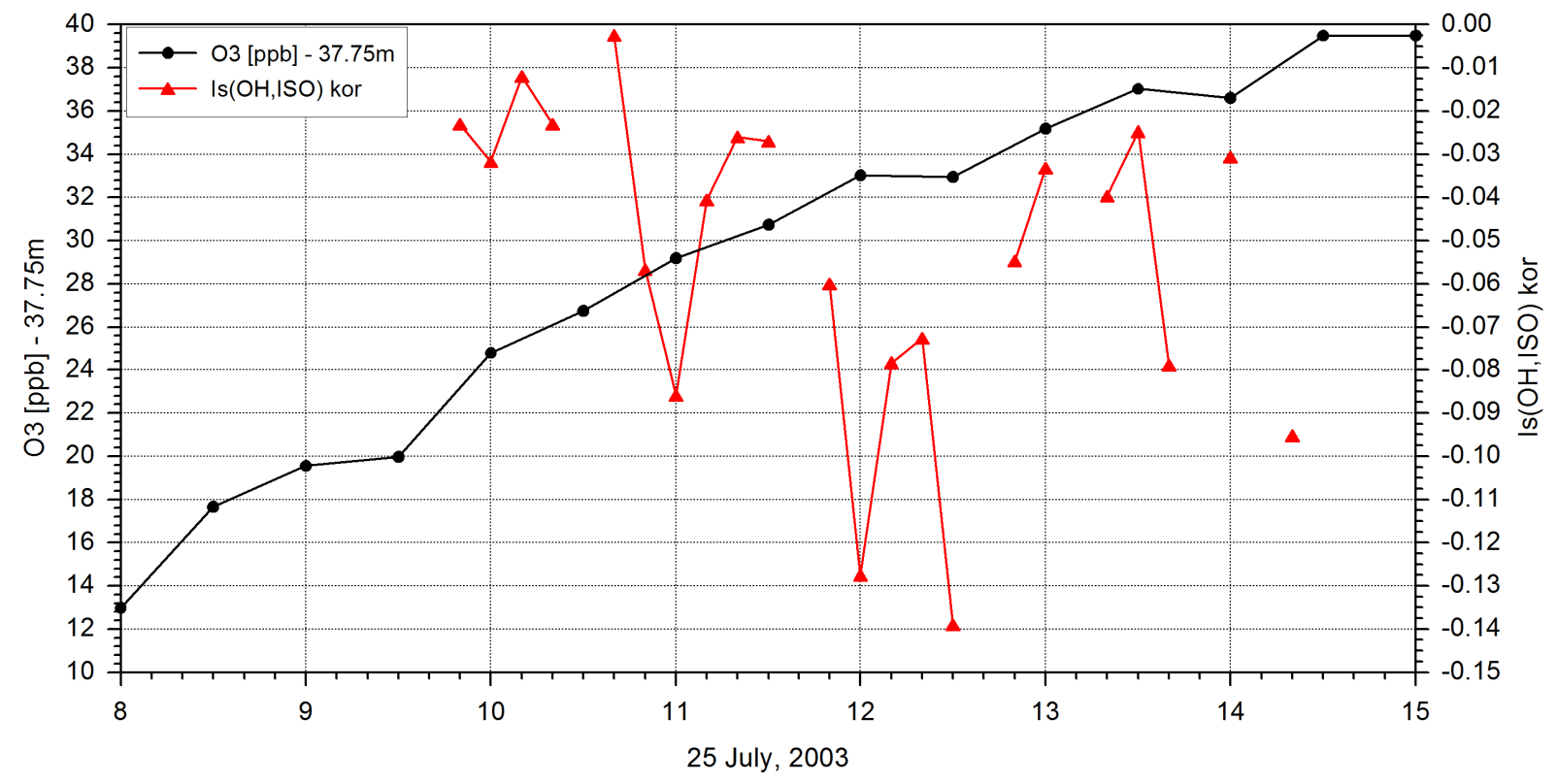

Figure 17: Mixing ratio of $\mathrm{O}_{3}$ and $I_{S}$ as function of time at the main tower on 25 July 2003, 09:0015:00 CET. 


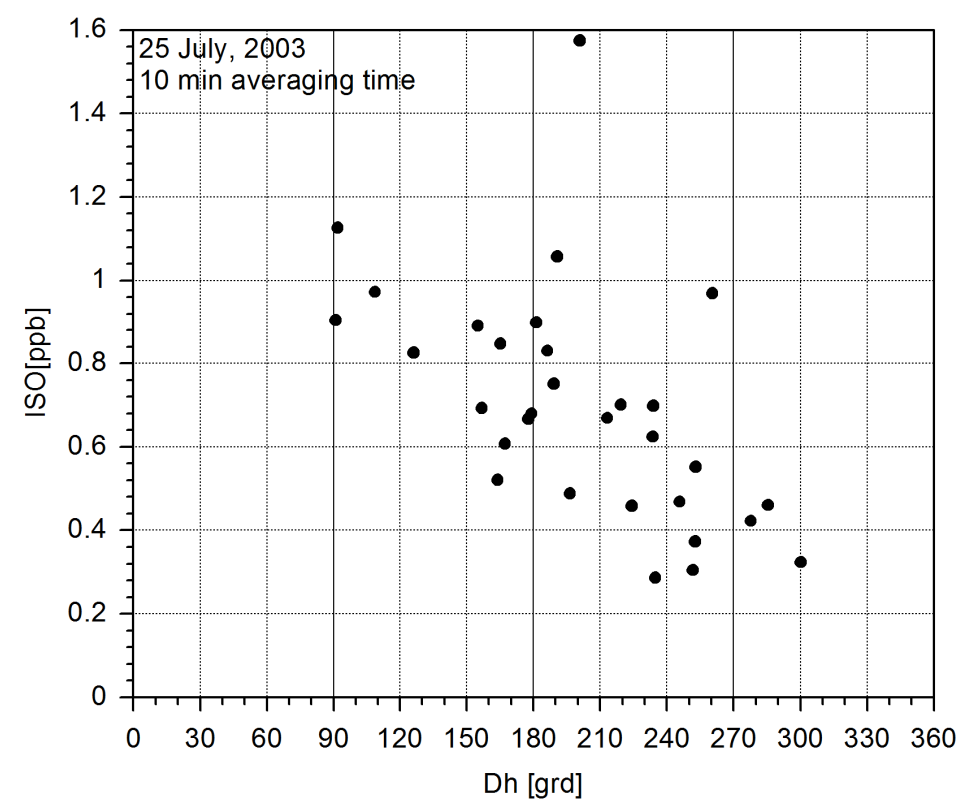

Figure 18: Mean isoprene mixing ratio as function of wind direction at the main tower on 25 July 2003 , 09:00-15:00 CET (for $D_{h}$ see also Figs. 21 and 25).

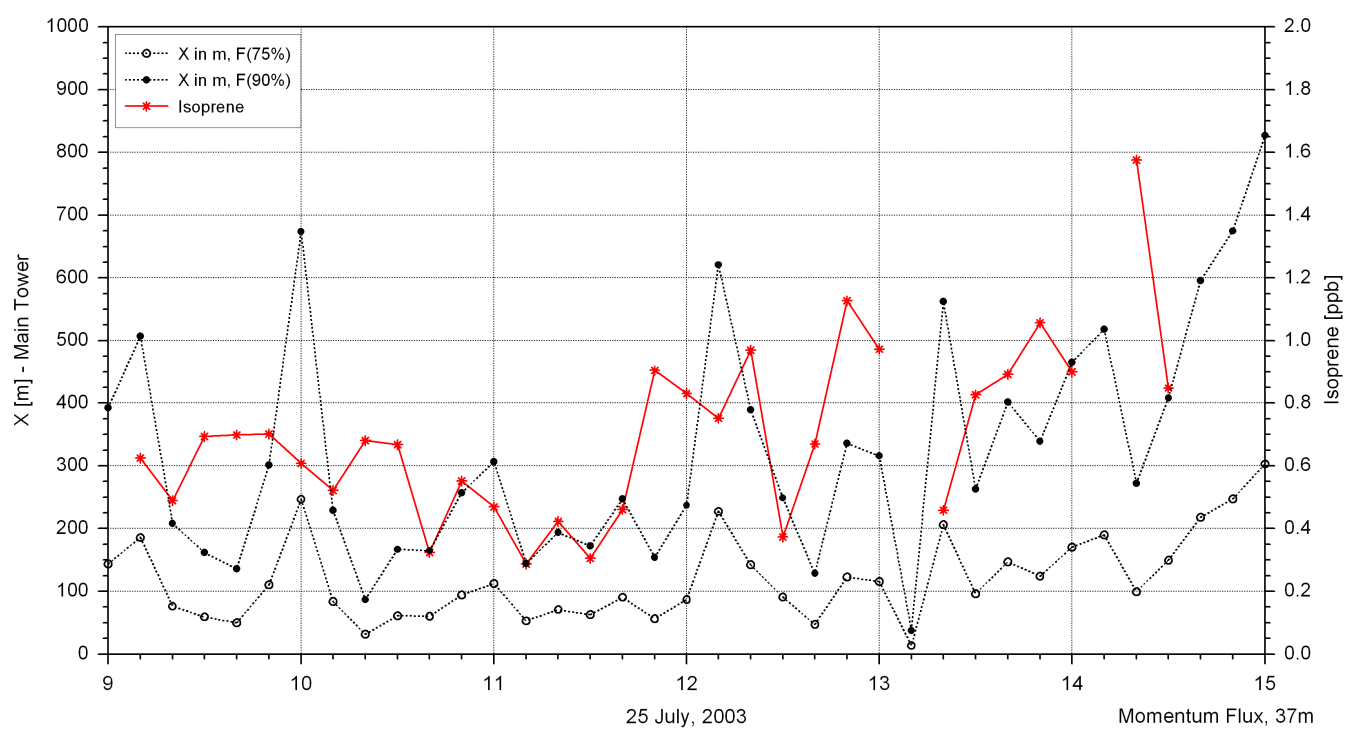

Figure 19: Footprint for the $75 \%$ and $90 \%$ cumulative flux of momentum (see text) and mean isoprene mixing ratio as function of time at the main tower on 25 July 2003, 09:00-15:00 CET. 


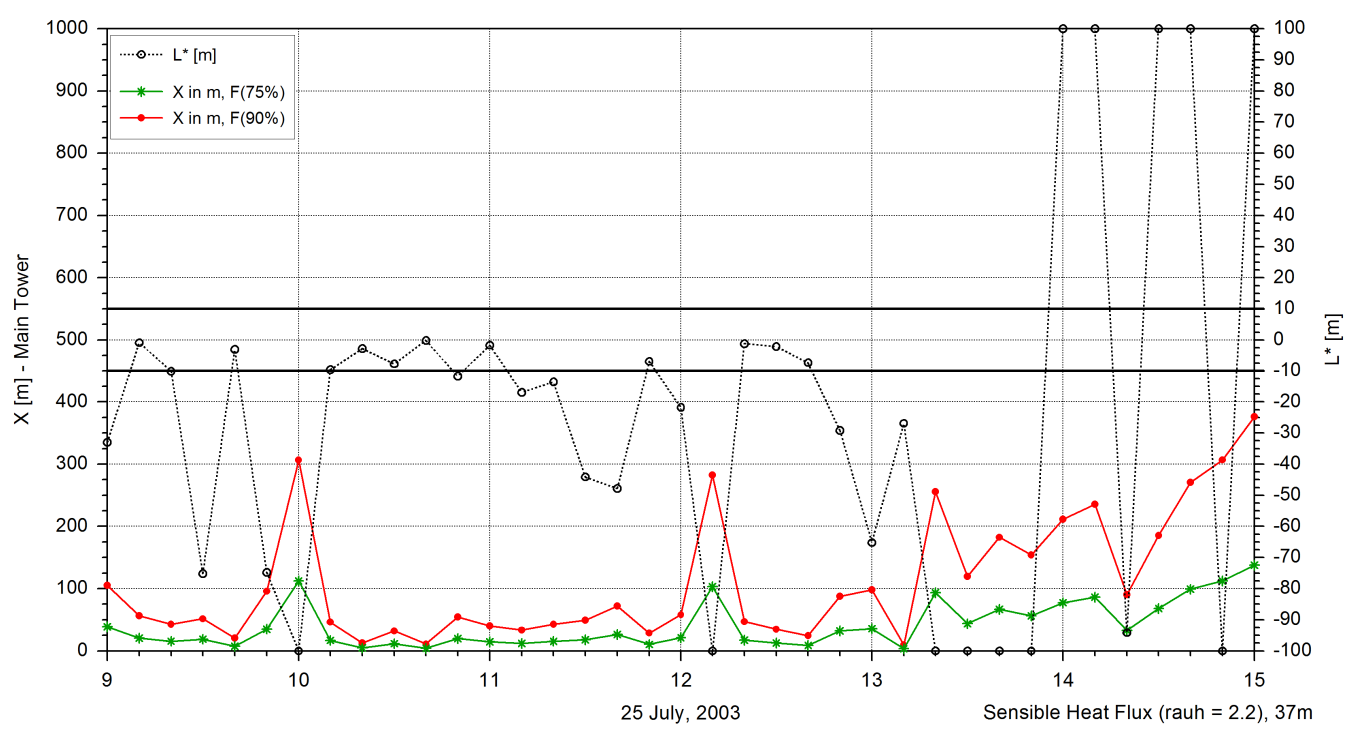

Figure 20: Footprint for the $75 \%$ and $90 \%$ cumulative flux of sensible heat for a rough surface (roughness parameter 2.2) and Monin Obukhov length $L_{*}$ as function of time at the main tower on 25 July 2003, 09:00-15:00 CET.

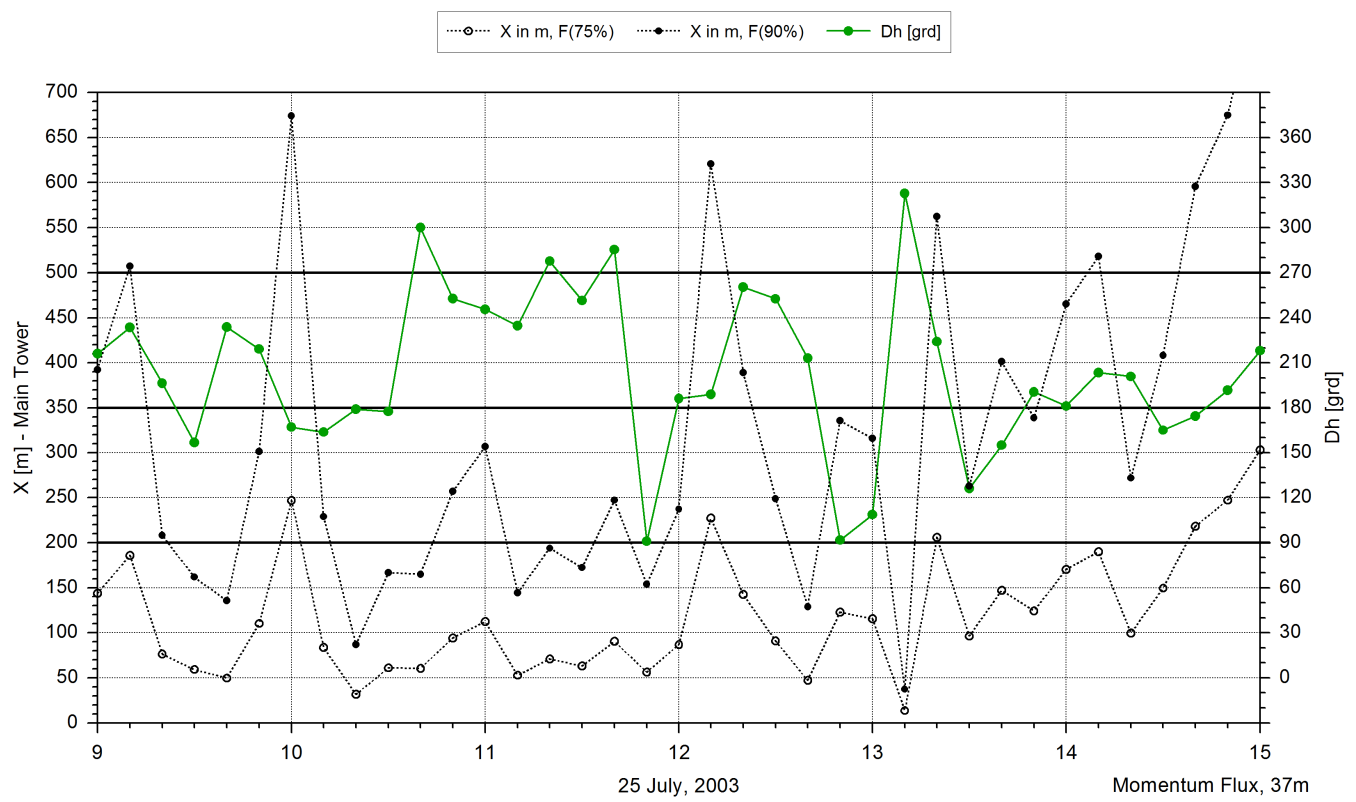

Figure 21: Footprint for the $75 \%$ and $90 \%$ cumulative flux of momentum (see text) and horizontal wind direction $D_{h}$ as function of time at the main tower on 25 July 2003, 09:00-15:00 CET. 


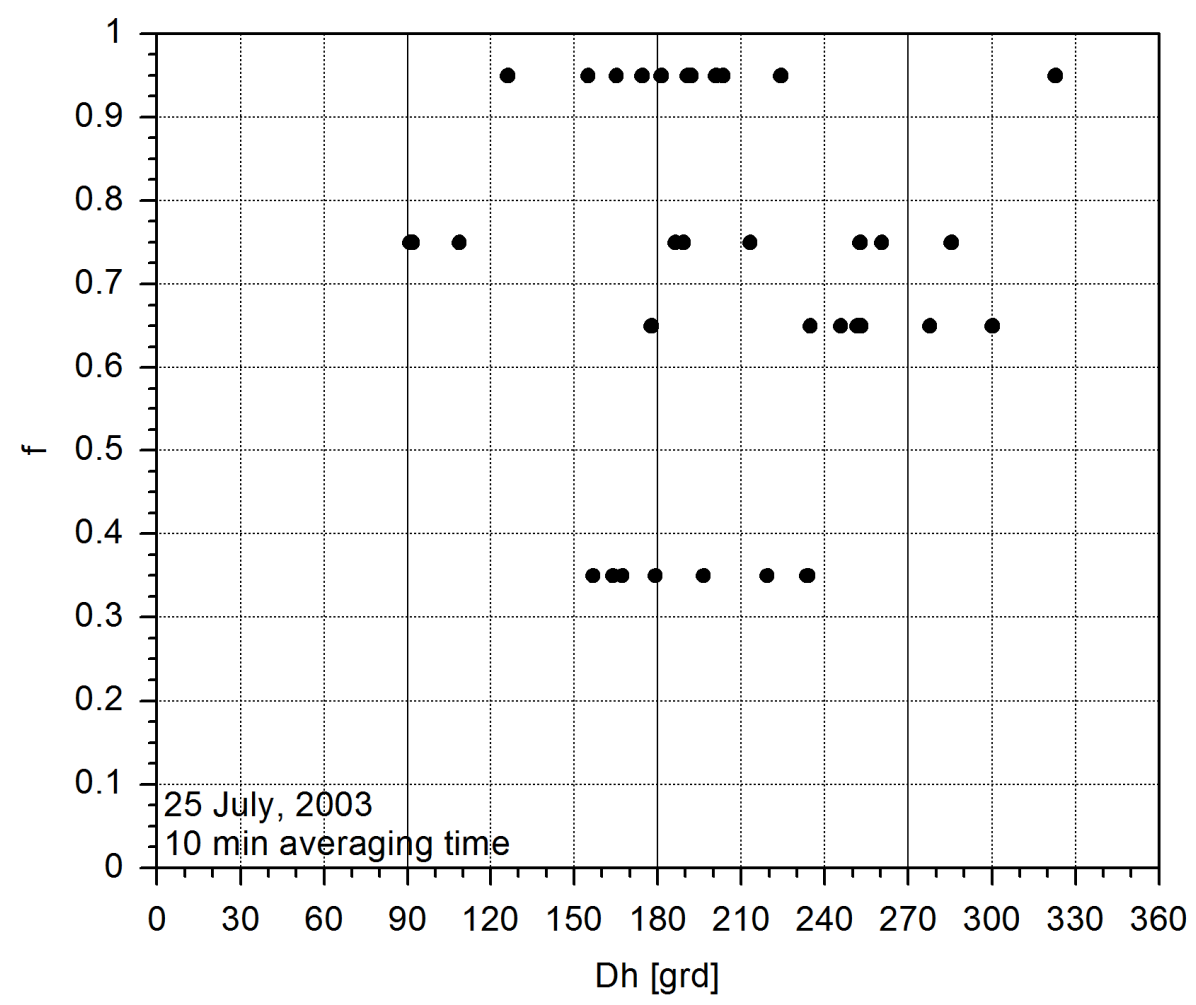

Figure 22: Factor $f$ from Eq. 4 as function of horizontal wind direction at the main tower on 25 July 2003, 09:00-15:00 CET.

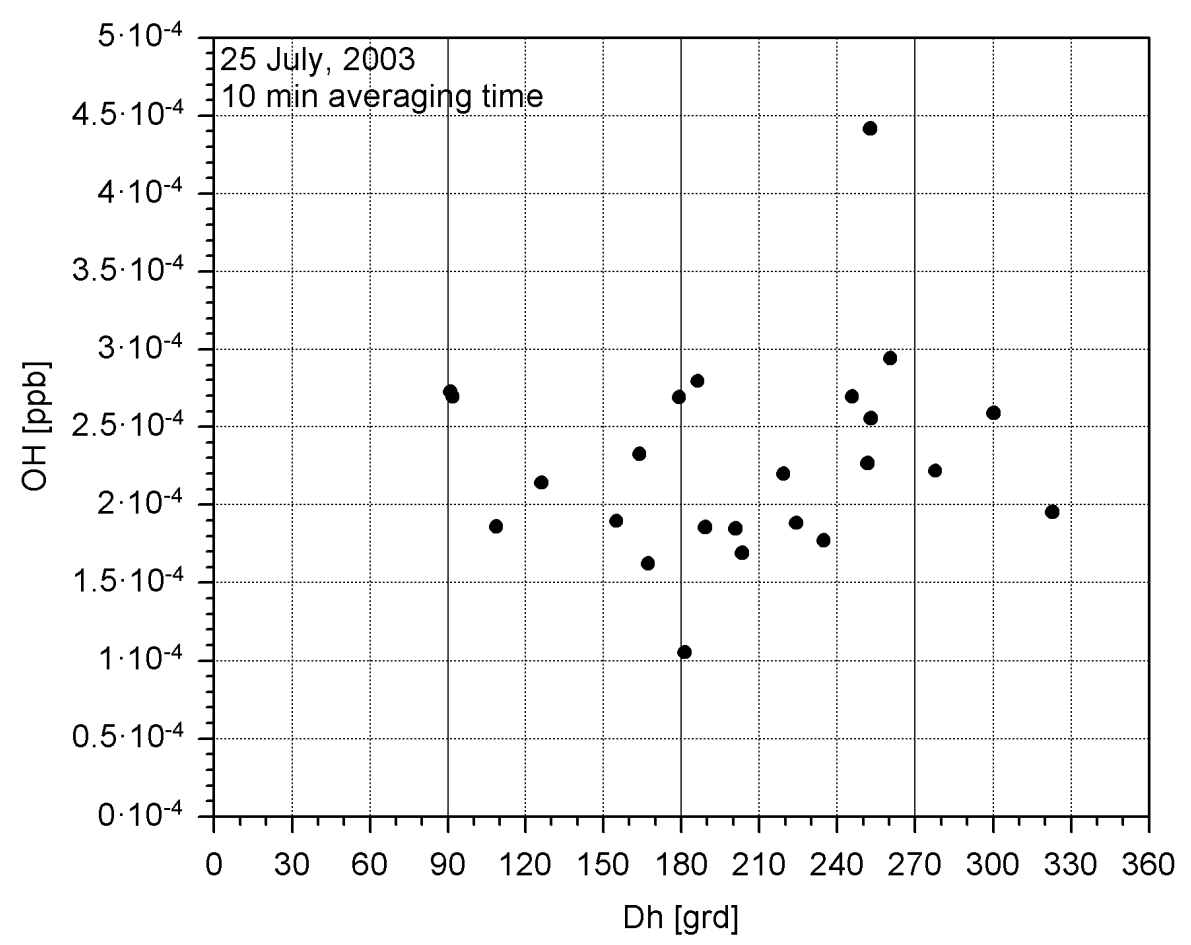

Figure 23: The mean $\mathrm{OH}$ mixing ratio at $37 \mathrm{~m}$ as function of horizontal wind direction at the main tower on 25 July 2003, 09:00-15:00 CET. 


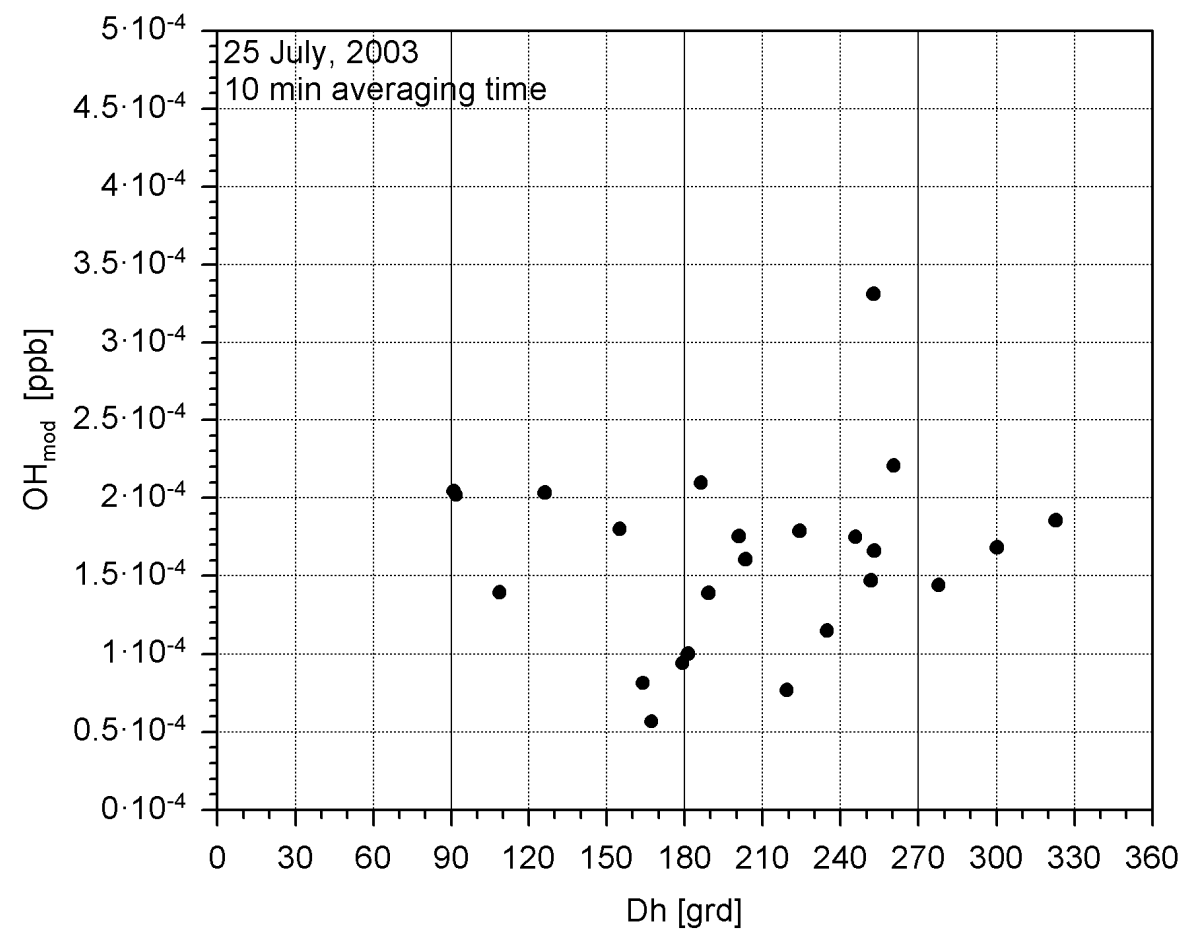

Figure 24: The mean $\mathrm{OH}_{\text {mod }}$ mixing ratio at $37 \mathrm{~m}$ as function of horizontal wind direction at the main tower on 25 July 2003, 09:00-15:00 CET. 


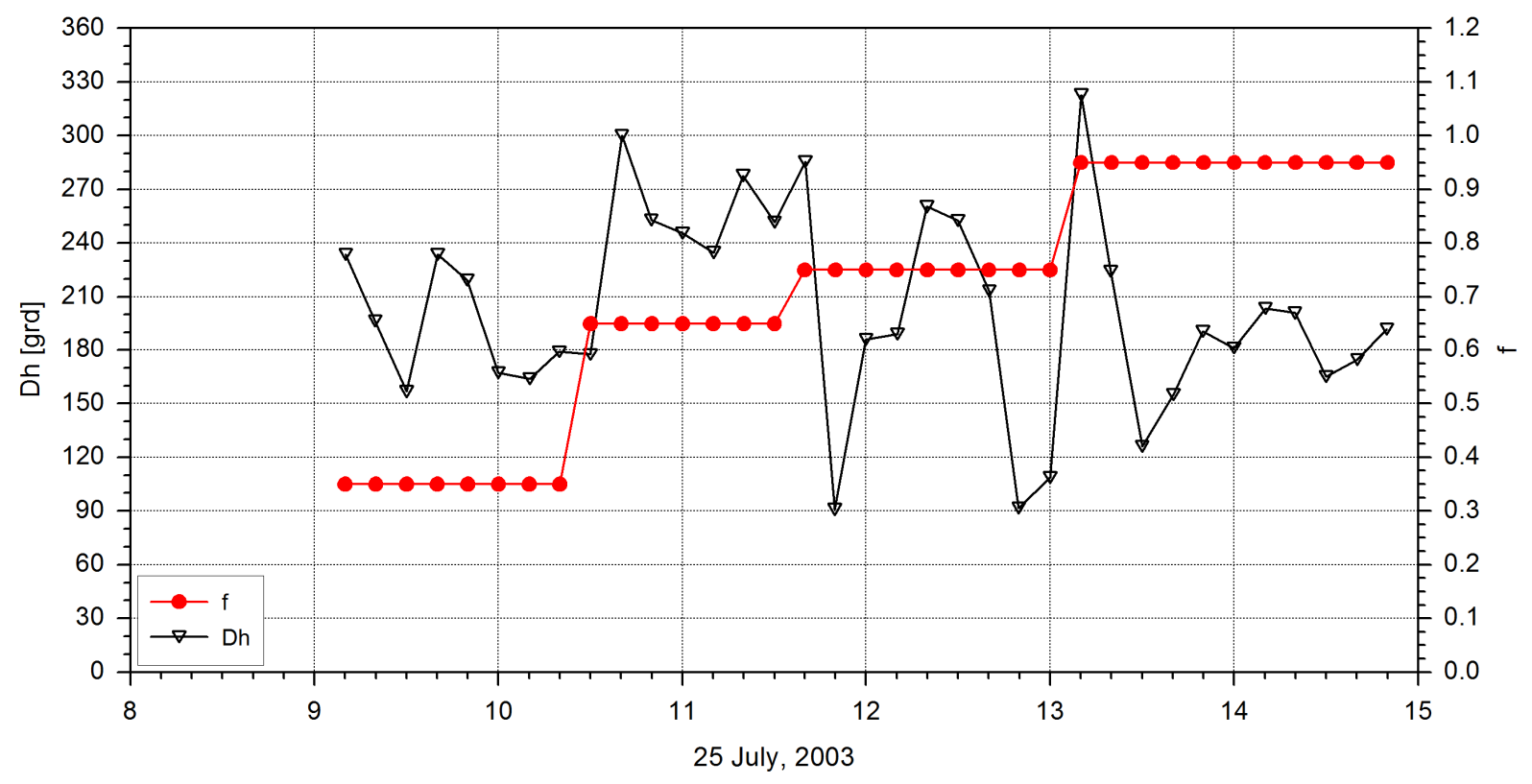

Figure 25: The factor $f$ and horizontal wind direction $D h$ as function of time at the main tower on 25 July 2003, 09:00-15:00 CET.

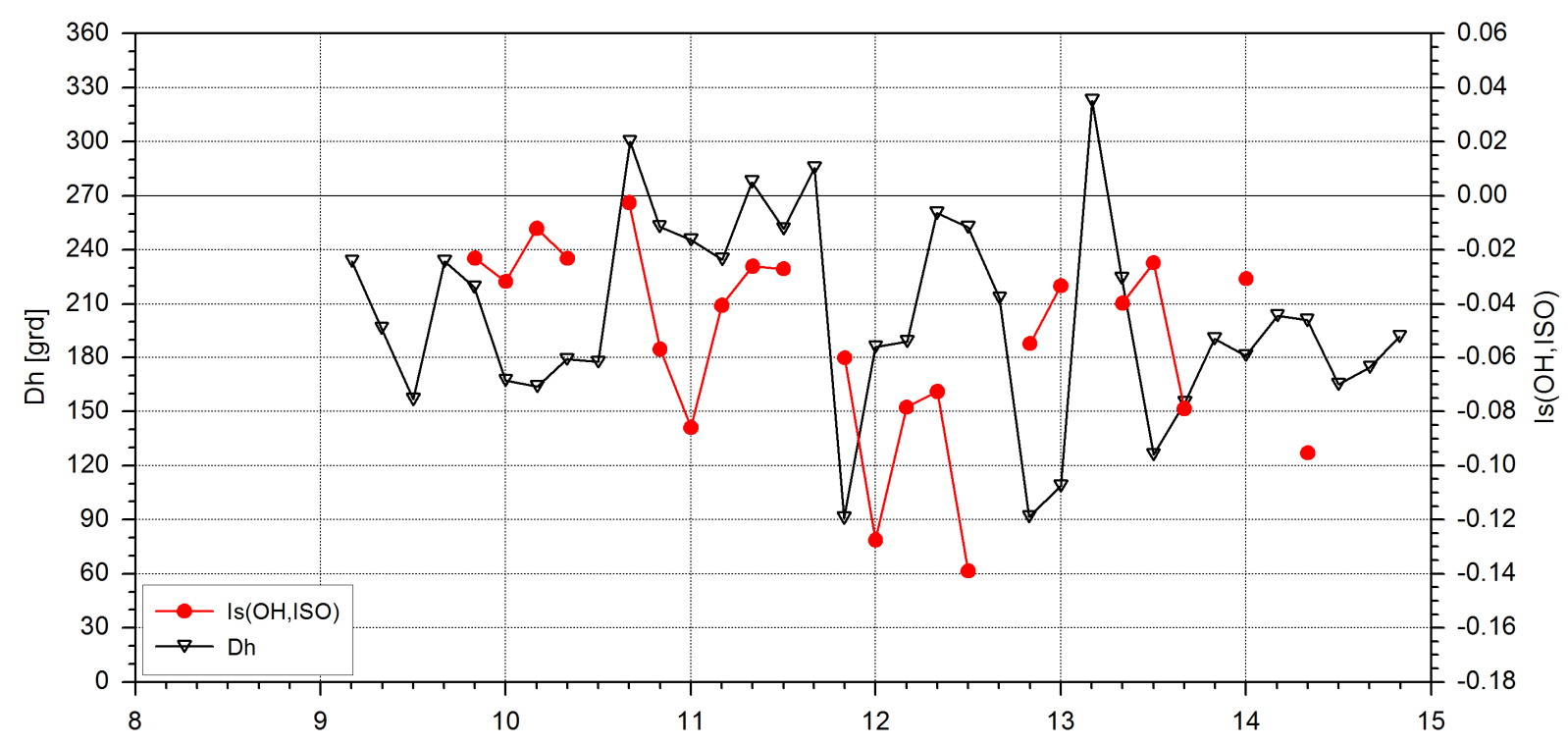

Figure 26: Horizontal wind direction and $I_{S}$ as function of time at the main tower on 25 July 2003, 09:00-15:00 CET. 


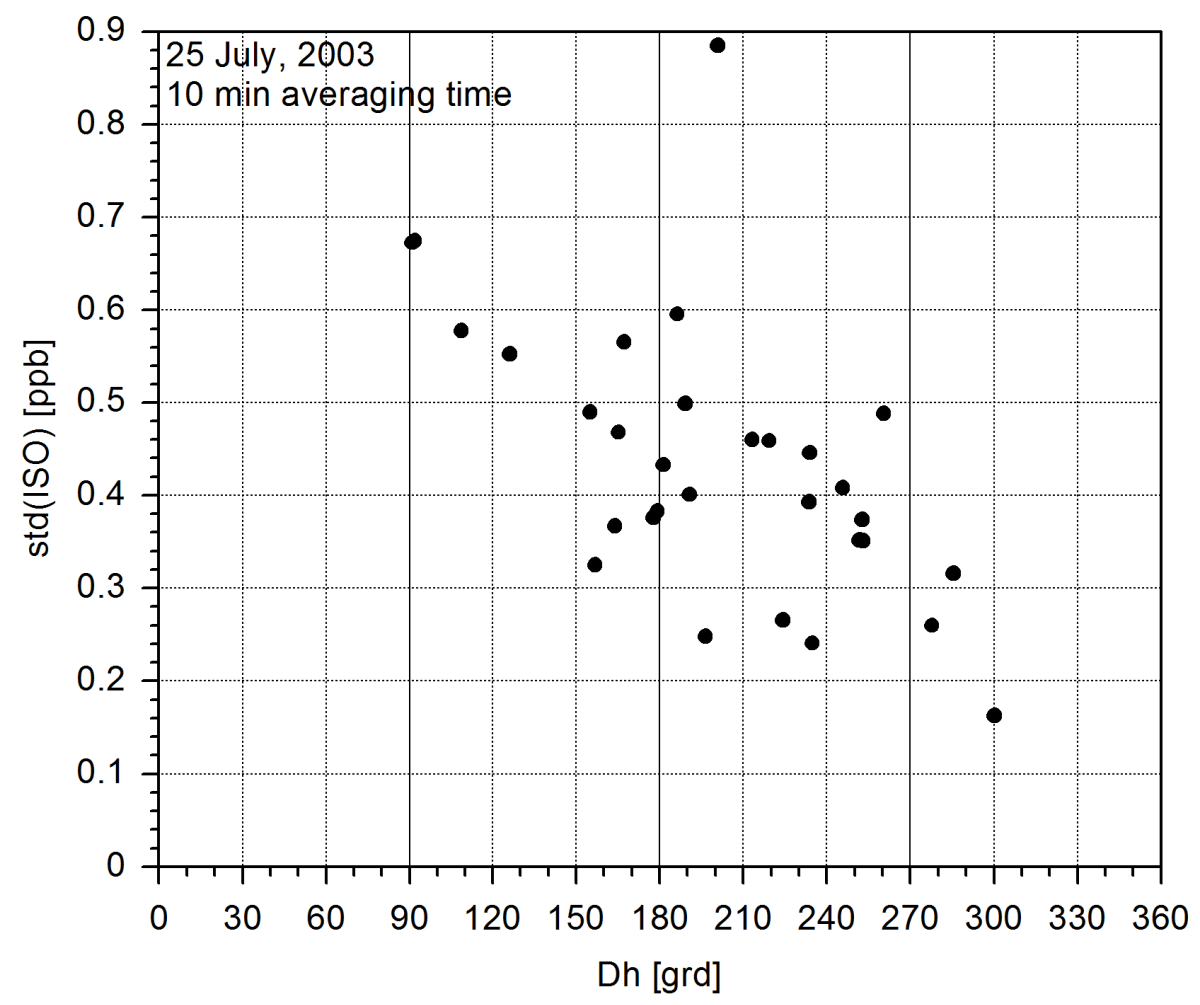

Figure 27: Standard deviation of isoprene as function horizontal wind direction at the main tower on 25 July 2003, 09:00-15:00 CET.

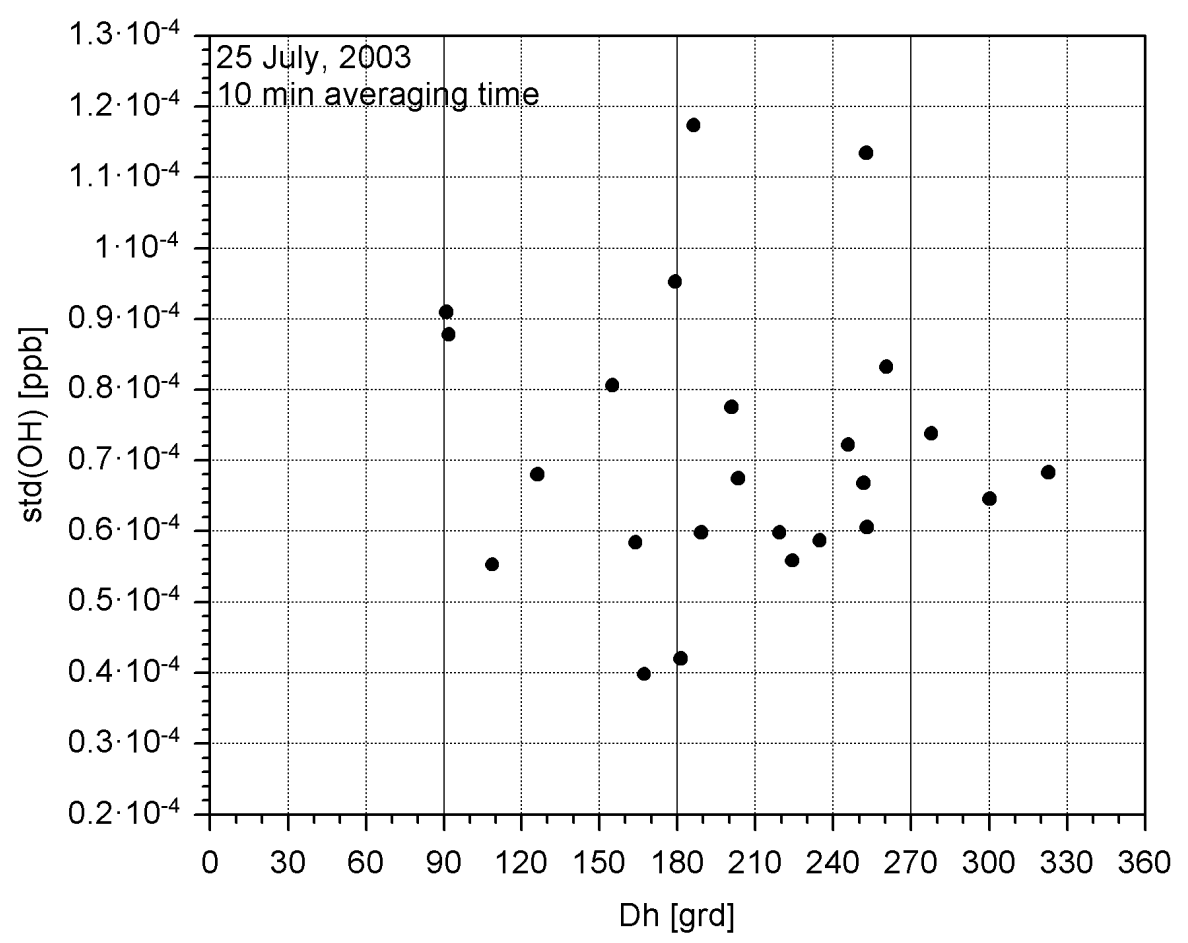

Figure 28: Horizontal wind direction and standard deviation of $\mathrm{OH}$ as function of time at the main tower on 25 July 2003, 09:00-15:00 CET. 


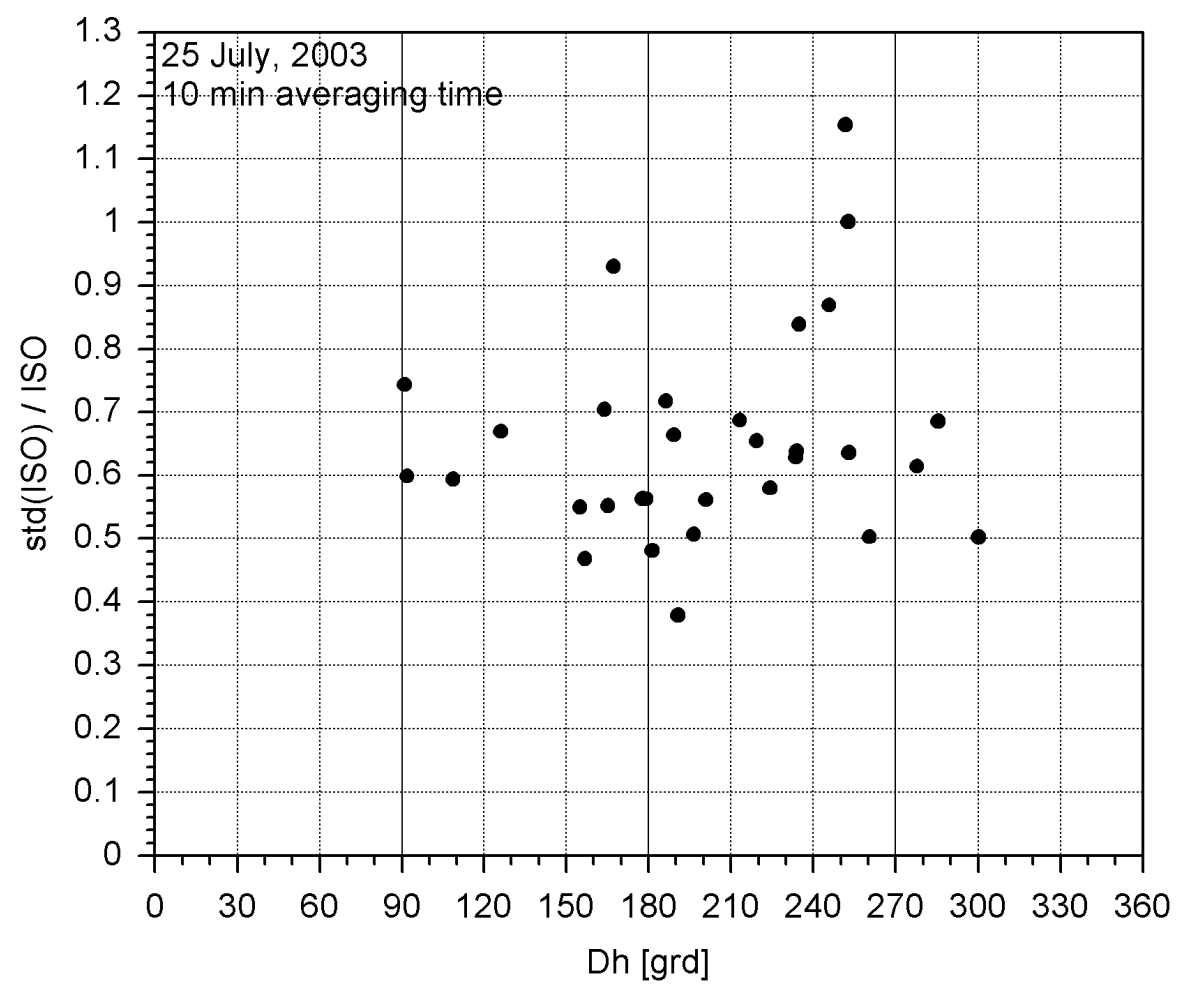

Figure 29: Normalized standard deviation of isoprene as function of horizontal wind direction at the main tower on 25 July 2003, 09:00-15:00 CET.

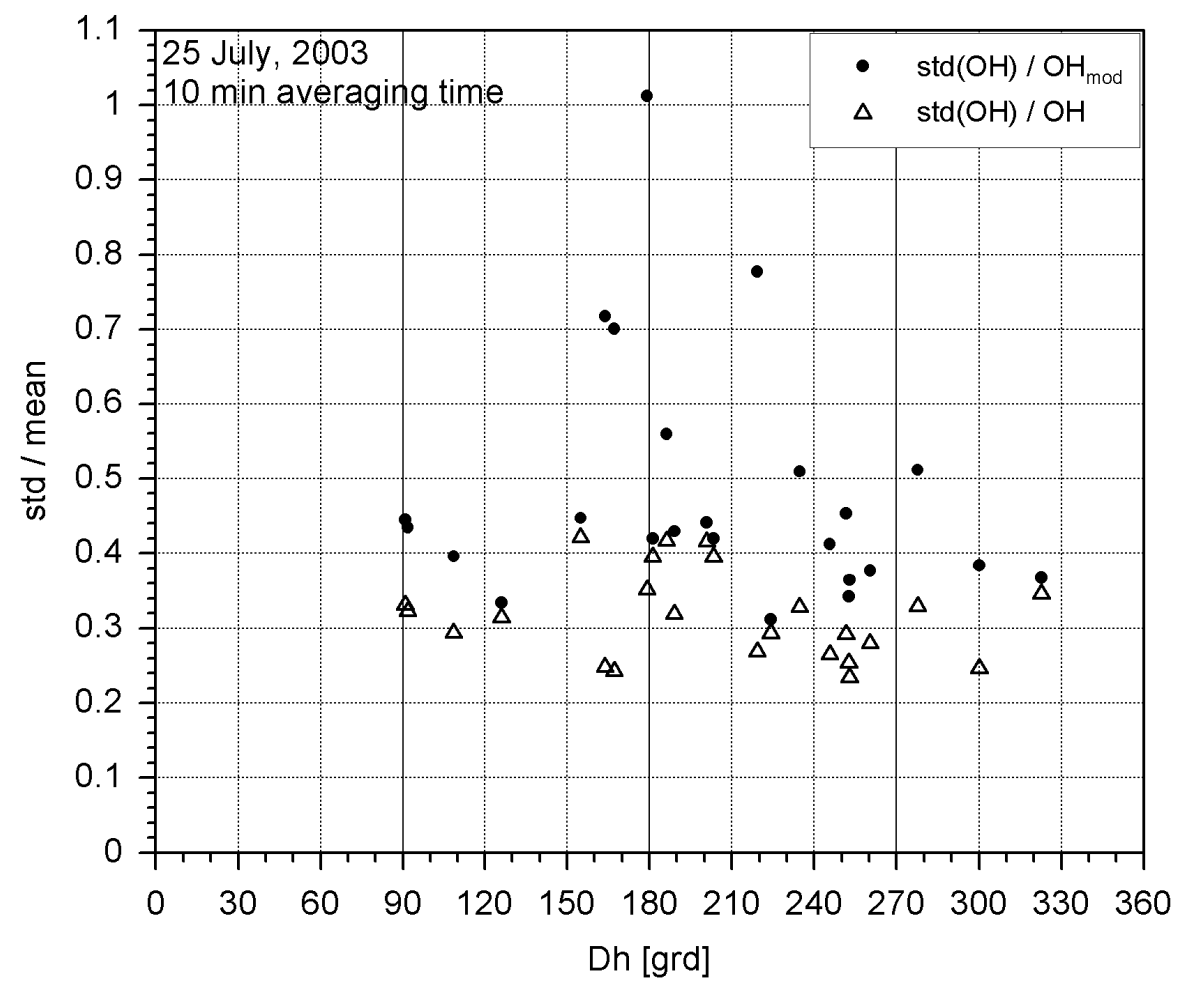

Figure 30: Normalized standard deviation of $\mathrm{OH}$ and $\mathrm{OH}_{m o d}$ as function of horizontal wind direction at the main tower on 25 July 2003, 09:00-15:00 CET. 


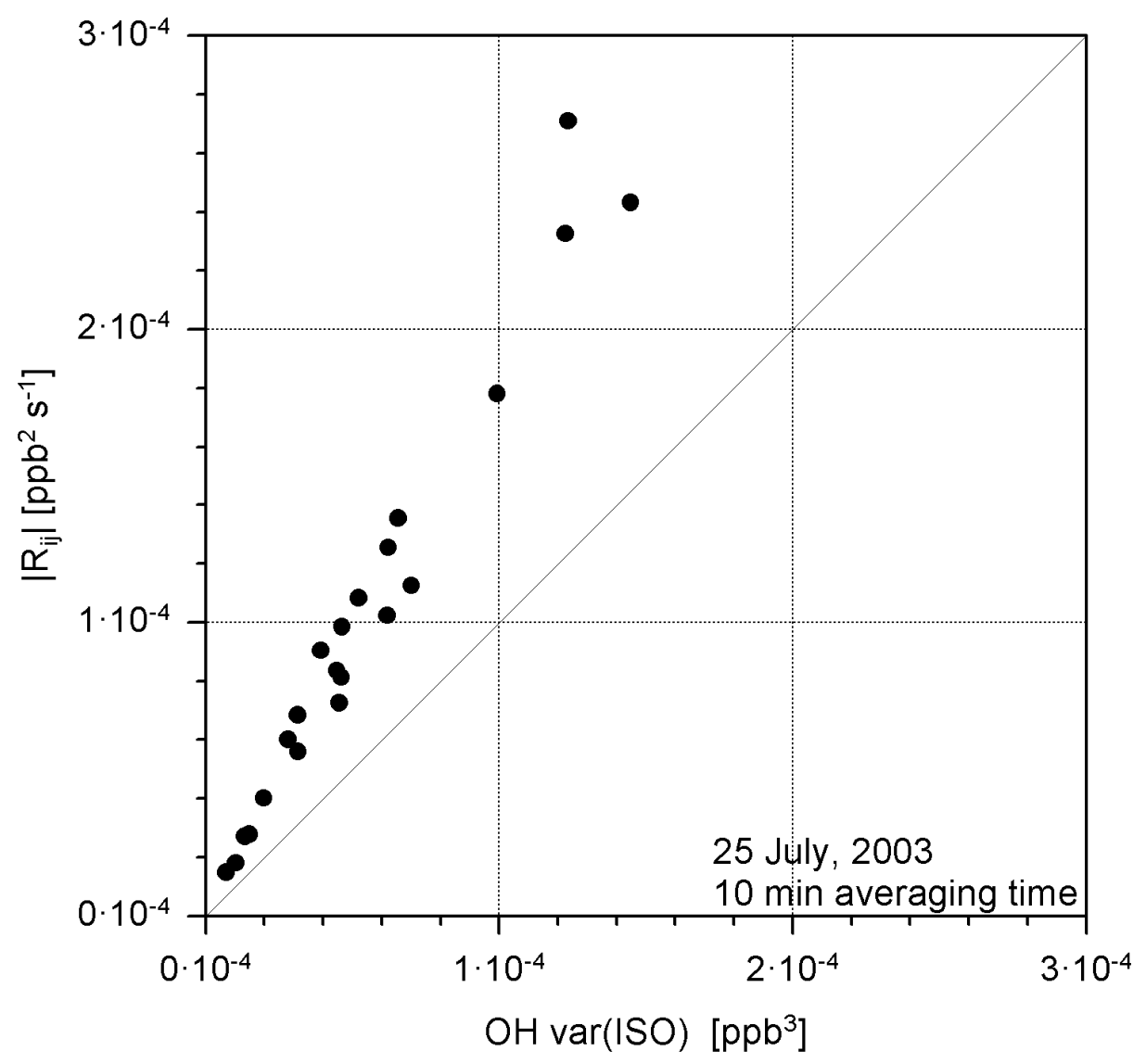

Figure 31: The magnitude of $R_{i j}$ as function of the third term of Eq. 10

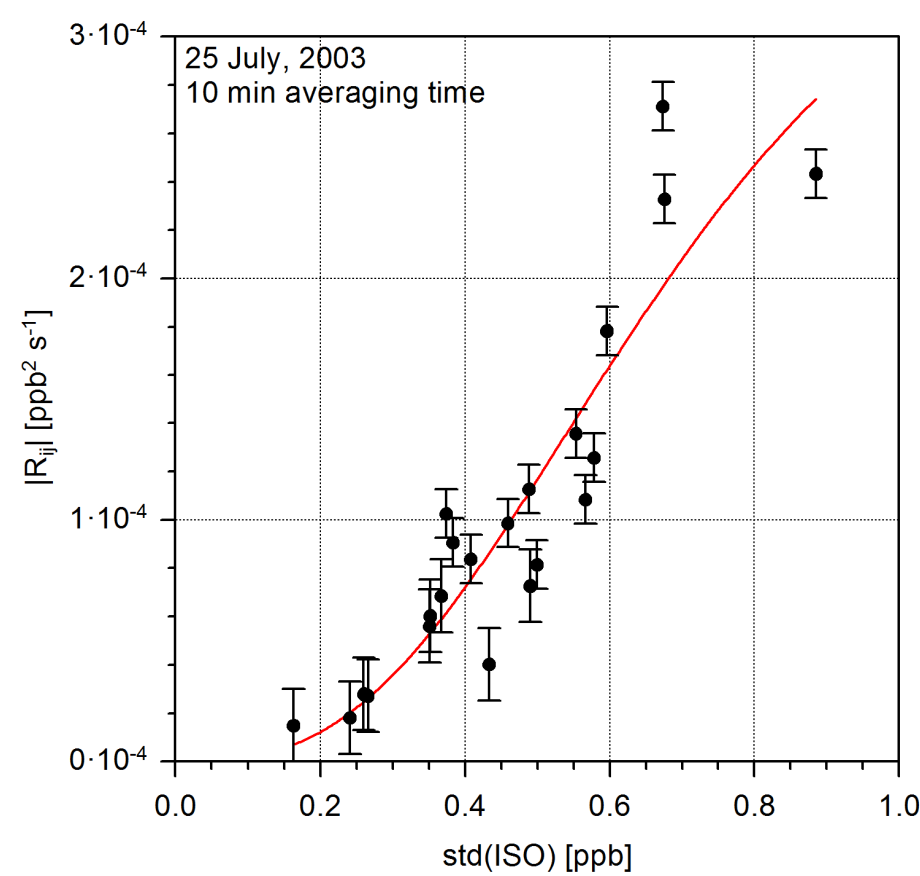

$\mathrm{R}_{\mathrm{ij}}$
non-linear regression: $(\mathrm{N}=22)$
$\mathrm{a} /\left(1+(\mathrm{b} / \mathrm{x})^{\wedge} \mathrm{C}\right)$
$\#$ Sigmoid\# $\mathrm{S}=.01 ; \mathrm{xE}=1 ; \mathrm{a}=1 ; \mathrm{b}=0.5 ; \mathrm{C}=5 ;$
$0,163<=\mathrm{x}<=0,885$
Least square minimized
iterations: 6
Goodness of Fit:
Chi ${ }^{2}=0, \mathrm{p}=0$
parameter:
$\mathrm{a}=0,0004 \pm 6,354$
$\mathrm{~b}=0,7027 \pm 7.832,6628$
$\mathrm{C}=2,7842 \pm 27.138,1239$
estimated with $1 / \mathrm{n}:$
variance of residues $=8,1499 \mathrm{E}-010$
standard deviation of residues $=2,8548 \mathrm{E}-005$
estimated with $1 /(\mathrm{n}-3)$ :
variance of residues $=9,4367 \mathrm{E}-010$
standard deviation of residues $=3,0719 \mathrm{E}-005$
correlation coefficient $=0.9146$
$\mathrm{df}^{2}=19$
$\mathrm{p}<=0.00001$
Eta ${ }^{2}=0.8364$
Eta ${ }^{2}$ adj. $=0.8192$

Figure 32: Empirical relation between $R_{i j}$ and $\sigma((I S O))$ with parameter for the trend line. 


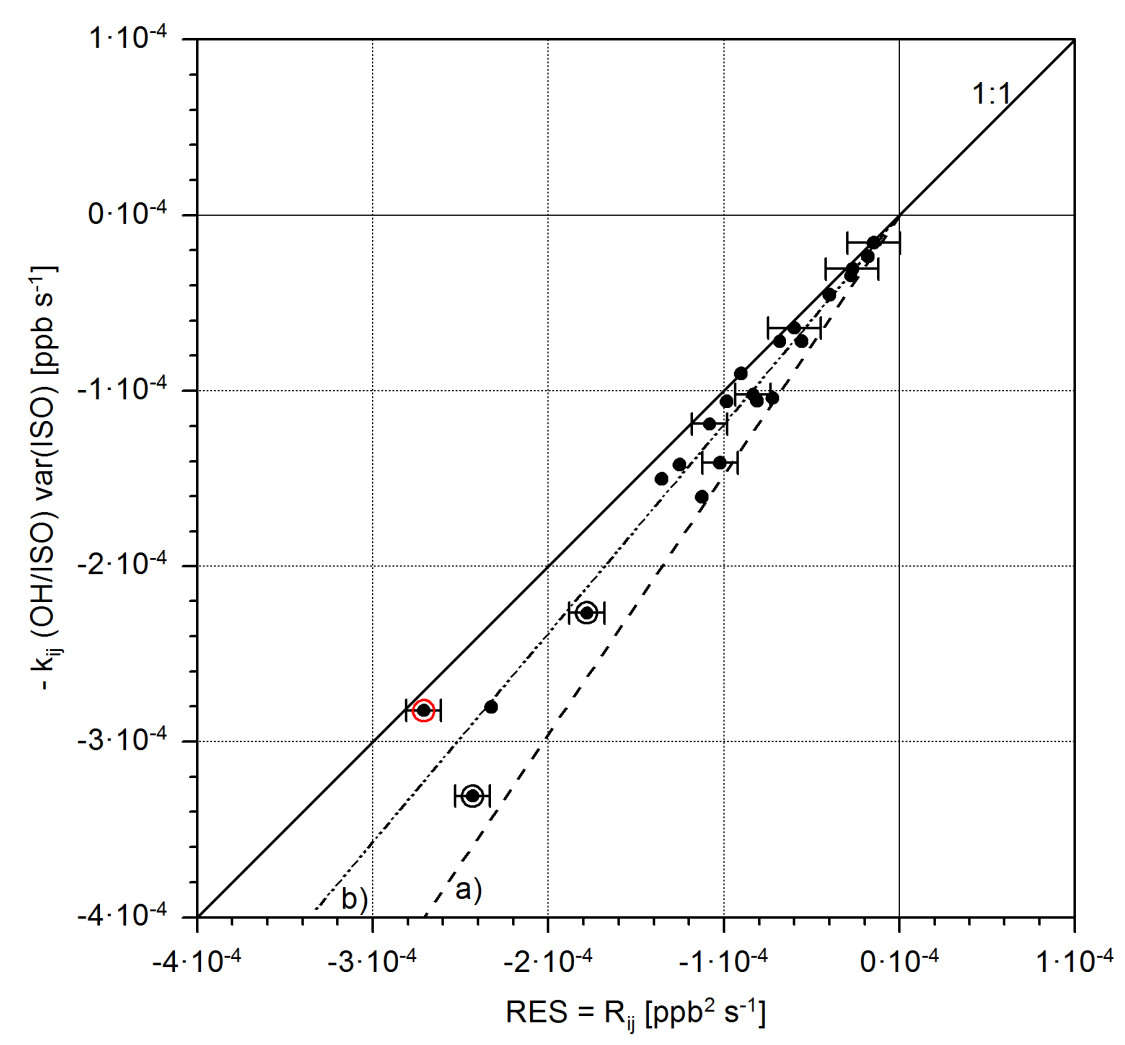

Figure 33: The term $k_{i j} \cdot(\overline{\mathrm{OH}} / \overline{\mathrm{ISO}}) \cdot \operatorname{var}(I S O)$ as function of term $R E S$ for 25.07.2003 (09:00-15:00 CET) The three marked points are discussed in the text. The dotted line is a fit to the data. The broken line a) and the 1:1 line are the borders for all data points.

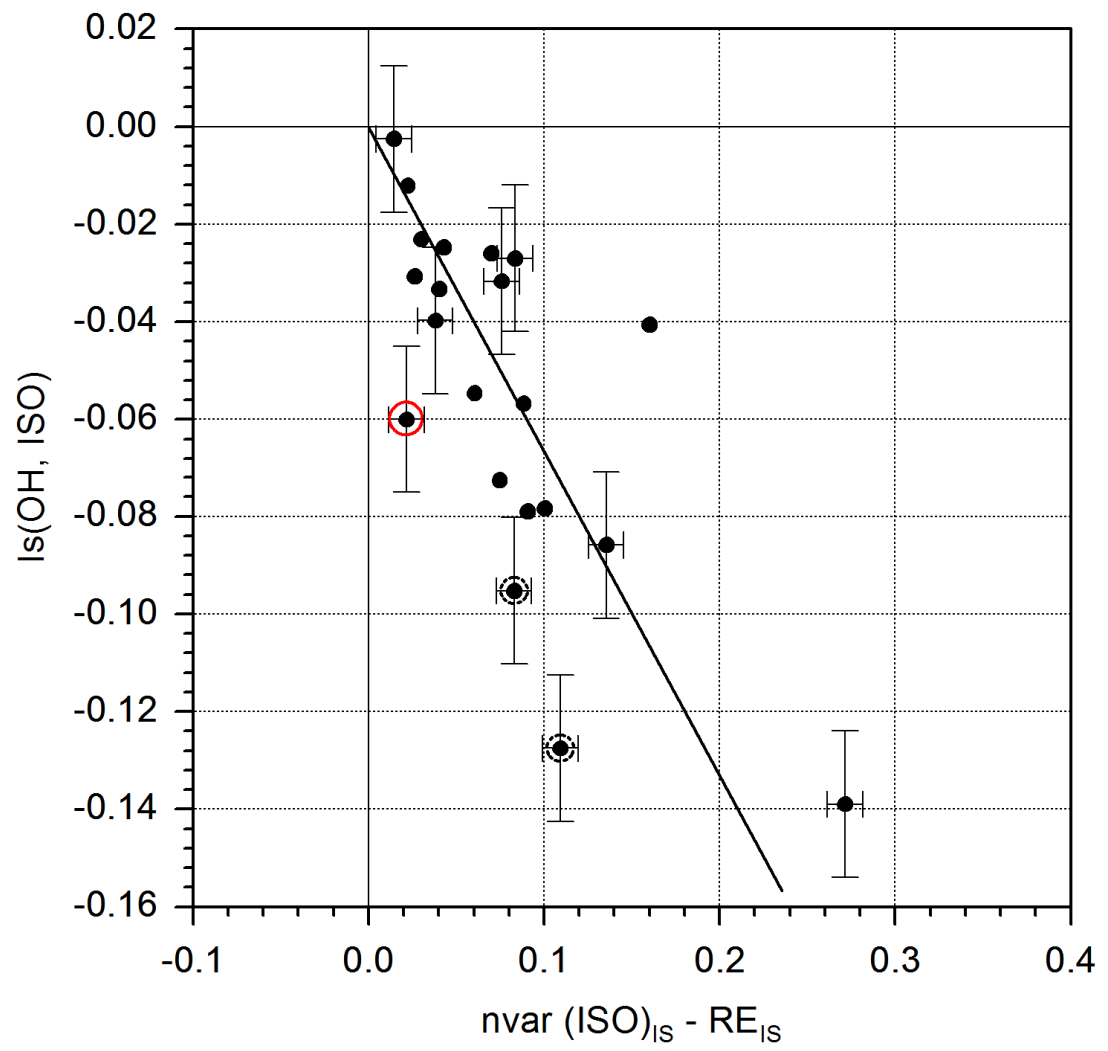

Figure 34: The intensity of segregation as function of the difference $n v a r(I s o)_{I S}-R E_{I S}$ according Eq. 16 as explained in the text. The straight line is a fit to the data. 